\title{
Targeting Epithelial Mesenchymal Plasticity in Pancreatic Cancer: A Compendium of Preclinical Discovery in a Heterogeneous Disease
}

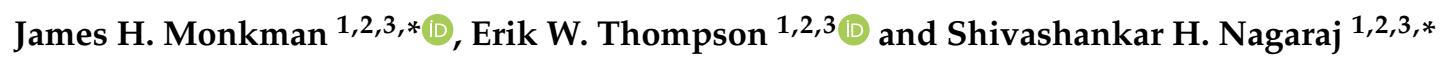 \\ 1 Institute of Health and Biomedical Innovation, Queensland University of Technology, Brisbane, QLD 4059, \\ Australia; e2.thompson@qut.edu.au \\ 2 School of Biomedical Sciences, Queensland University of Technology, Brisbane, QLD 4059, Australia \\ 3 Translational Research Institute, Brisbane, QLD 4102, Australia \\ * Correspondence: james.monkman@qut.edu.au (J.H.M.); shiv.nagaraj@qut.edu.au (S.H.N.)
}

Received: 8 August 2019; Accepted: 30 October 2019; Published: 7 November 2019

\begin{abstract}
Pancreatic Ductal Adenocarcinoma (PDAC) is a particularly insidious and aggressive disease that causes significant mortality worldwide. The direct correlation between PDAC incidence, disease progression, and mortality highlights the critical need to understand the mechanisms by which PDAC cells rapidly progress to drive metastatic disease in order to identify actionable vulnerabilities. One such proposed vulnerability is epithelial mesenchymal plasticity (EMP), a process whereby neoplastic epithelial cells delaminate from their neighbours, either collectively or individually, allowing for their subsequent invasion into host tissue. This disruption of tissue homeostasis, particularly in PDAC, further promotes cellular transformation by inducing inflammatory interactions with the stromal compartment, which in turn contributes to intratumoural heterogeneity. This review describes the role of EMP in PDAC, and the preclinical target discovery that has been conducted to identify the molecular regulators and effectors of this EMP program. While inhibition of individual targets may provide therapeutic insights, a single 'master-key' remains elusive, making their collective interactions of greater importance in controlling the behaviours' of heterogeneous tumour cell populations. Much work has been undertaken to understand key transcriptional programs that drive EMP in certain contexts, however, a collaborative appreciation for the subtle, context-dependent programs governing EMP regulation is needed in order to design therapeutic strategies to curb PDAC mortality.
\end{abstract}

Keywords: pancreatic cancer; epithelial mesenchymal plasticity; target discovery; review

\section{Pancreatic Cancer, Tumour Heterogeneity, and Carcinoma Vulnerabilities}

Pancreatic cancer (PC) is the fourth most common cause of cancer-related deaths in Western societies, with 57,000 new cases annually, resulting in nearly 46,000 deaths in North America alone [1]. The most common type of PC is Pancreatic Ductal Adenocarcinoma (PDAC), which arises in the ductal epithelium of the exocrine tissue responsible for secreting pancreatic digestive juices. Late detection combined with early metastatic spread have limited gains in overall survival relative to other cancers such that PDAC mortality has the potential to surpass that of both colorectal and breast cancers by 2030 [2]. PDAC research therefore aims to define better diagnostic markers and novel therapeutic avenues, however is significantly complicated by the clinical heterogeneity present both within and between patient tumours. This emphasises the need for more integrative approaches aimed at developing a better understanding of targetable processes in PDAC tumourigenesis. 
Cancer is a genetic disease caused by the accumulation of somatic mutations, resulting in a functional imbalance between tumour suppressive and oncogenic signals [3]. While transformed cells retain characteristics of the host to efficiently avoid being detected as foreign by the immune system, many aberrant phenotypes caused by genetic mutations and dysregulated signaling potentially render these cells susceptible to selective therapeutic interventions. Extensive examinations of the molecular traits of PDAC aimed at identifying such vulnerabilities have been conducted to date. Indeed, genomic and transcriptional profiling of patient tumours as part of large-scale studies by the The Cancer Genome Atlas (TCGA) and International Cancer Genome Consortium (ICGC) have allowed for insights into the scale of inter-tumour heterogeneity in a breadth of patient cohorts [4-6].

These studies have identified four major genetic aberrations common to pancreatic tumours [7-9]. 90\% of tumours carry gain-of-function mutations in KRAS2, activating proliferative and cell survival pathways, whilst $95 \%$ contain either partial or complete inactivating mutations in CDKN2A, contributing to loss of cell cycle regulation, furthering proliferation. TP53, responsible for responding to DNA damage and inducing apoptosis, is altered in $60 \%$ of cases. SMAD4 inactivation is also common in pancreatic cancer development, and is found in $50 \%$ of patient cancers, disrupting the tumour suppressive signals of TGF $\beta$, aiding proliferation [10]. As well as these four common driver mutations, genomic sequencing of tumours has identified an additional panel of consistently mutated genes [6]. These genetic mutations implicate pathways often dysregulated in cancer, including KRAS, TGF $\beta$, WNT, NOTCH, ROBO/SLT, G1/S, SWI-SNF, and chromatin/DNA/RNA modification and repair.

Transcriptional profiling of PDAC tumours has allowed researchers to define discrete regulatory mechanisms within these networks that are associated with particular prognostic indices in different molecular subtypes of PDAC, which include squamous, pancreatic progenitor, immunogenic and aberrantly differentiated endocrine/ exocrine tumours [6]. Such classification schemes may provide clinical value by aiding in patient treatment regimen selection and planning [11], however, to date they have provided limited clinical value due to lack of targetable phenomena. It is important to note that while these studies have aimed to characterise changes within carcinoma cells, the excessive presence of desmoplastic stroma may confound these results. Indeed, microdissection of the tumour from its associated stroma has allowed the retrospective re-evaluation of large-scale transcriptional profiling efforts, highlighting the overwhelming contribution of stromal contamination to many such studies. Deconvolution based on laser capture microdissection and RNASeq profiling of 60 matched tumour/stroma pairs suggested that ICGC and TCGA samples contained stromal fractions of $46 \%$ and $55 \%$, respectively, highlighting difficulties in deriving definitive conclusions from whole tumour analyses [12].

Such studies are invaluable as a means of understanding the intertumoural heterogeneity that exists between patients, and they form a strong set of public data that have been analysed to better appreciate the diversity of tumour presentation [13]. An increasing focus on single cell analytic technologies has yielded exciting opportunities to understand the contributions that individual cells make towards intratumoural heterogeneity, tumour progression, and patient outcomes $[14,15]$. These studies highlight the need for efforts aimed at distinguishing the heterogeneous nature of a tumour's biology from that of the surrounding host tissue in which it propagates, so as to be better able to exploit cancer specific vulnerabilities [16].

As such, it is not surprising that the interactions between neoplastic epithelial cells and host myofibroblast and stellate populations, which can promote stromal inflammation, are increasingly being recognised. This desmoplastic reaction, which accounts for up to $90 \%$ of PDAC tumour volume, has pro-tumourigenic properties by leading to increased tissue stiffness and hypoxia as well as by providing physical barriers to both immune surveillance and chemotherapeutic penetrance [17-19]. The fibrillar collagen, hyaluronic acid and fibronectin rich extracellular matrix (ECM) deposited by stromal cells contains many soluble cytokines and growth factors secreted by both cancer and stromal compartments and contributes to both tumour initiation and progression [20-23]. Resident cells are forced to interact within this dynamic tumour microenvironment and are subject to stimuli that 
influence cell phenotypes in both stromal and carcinoma components. Such stimuli may propagate the invasion and dissemination of carcinoma cells by inducing epithelial mesenchymal plasticity (EMP), and thus this process is considered an important vulnerability that, when effectively targeted, may curb tumour progression $[24,25]$.

\section{EMP and PDAC Progression}

EMP is often separated into two distinct but related processes-the forward process of epithelial-mesenchymal transition (EMT), and the reverse process of mesenchymal-epithelial transition (MET) [26]. These programs serve to describe the plasticity within epithelial cells that enables them to dedifferentiate into a more motile mesenchymal state, thereby allowing them to more effectively migrate. EMP is thought to play a significant role in several stages of tumour formation [27] and progression [28]. Initially, this plasticity allows tumour cells to detach and migrate from their site of origin (invasion), gaining access to lymphatic and blood vessels (intravasation), and then penetrating distant sites (extravasation), to form metastases.

A litany of reviews regarding different facets of EMP in PDAC, have been written, including those focused on molecular mechanisms of EMP regulation and metastasis [29-36], the role of epigenetic regulation [37], therapy development and resistance [38-42], microRNA regulation [43,44], and cancer stem cell generation [45-49]. This review thus focuses on some of the ongoing controversy surrounding in vivo evidence of EMP and the limitations of current approaches, highlighting the need to integrate a greater diversity of published EMP molecular regulators.

Development of PDAC frequently progresses undetected, remaining asymptomatic until it becomes an advanced stage of disease. Non-invasive precursor lesions formed either by epithelial proliferations or mucinous cysts in the pancreatic ducts, termed pancreatic intraepithelial neoplasia (PanINs), or intraductal papillary mucinous neoplasms (IPMNs), respectively, mark the onset of a histologically definable neoplasm in PDAC [50]. Such neoplasms, namely PanINs, progress through stages of dysplasia within the ductal epithelium, giving rise to the most common form of PDAC, pancreatic ductal adenocarcinoma (PDAC). The full breadth of factors that contribute to the invasive and metastatic behaviour of PDAC are vast. In this form of PDAC, there is very little latency between primary tumour formation and local and distant metastasis, implying that PDAC carcinoma cells may be readily equipped to invade and disseminate from a very early stage of development $[51,52]$.

Invasive regions of human carcinomas are typically characterised by the presence of tumour-derived, fibroblast-like cells expressing mesenchymal markers such as vimentin, fibronectin and N-cadherin, with decreased expression of epithelial adhesion molecule E-Cadherin and increased nuclear beta-catenin relative to surrounding cells [53-57]. Decreased expression of E-cadherin has been shown to correlate with invasive and undifferentiated PDAC [58]. Furthermore, PDAC patients with tumour cells that express decreased E-cadherin and higher amounts of vimentin, s100A4, fibronectin and SNAI1 are more likely to have distant metastases, lymph node invasion and lower overall survival [54,59-62]. The EMP inducing transcription factor (TF) TWIST1 has been shown to be upregulated in PDAC compared to match normal tissues [63], and SNAI1 mRNA levels in PDAC fine needle aspirates are significantly correlated with lymph node and perineural invasion as well as with poorer survival [64]. A mediator of transforming growth factor beta (TGF $\beta$ ) signaling, SMAD3, was also shown to accumulate in the nucleus of PDAC samples, and was correlated with higher grade tumours and lymph node metastasis, indicating a role for TGF $\beta$ in driving EMP in vivo [65]. Solitary infiltrating cancer cells displaying low E-cadherin and increased vimentin expression have proven to be significant prognostic indicators in resected clinical specimens from PDAC patients [66]. Tumour budding cells in PDAC have been observed with increased levels of ZEB1 and ZEB2, and reduced levels of E-cadherin and $\beta$-catenin, indicative of EMP mediated local invasion. ZEB2 overexpression in tumour-stroma associated cells also correlated with pathological assessment of tumour size, and lymph node metastasis [67]. Such striking pathology provides some of the clearest evidence for the role of EMP in PDAC progression. 
While this clinical evidence strongly supports a role for EMP in mediating cancer invasion, the inability to accurately follow carcinoma epithelial dedifferentiation in vivo has led to some debate surrounding the extent of its role in tumour progression $[68,69]$. Such debate has necessitated the use of genetically engineered mouse models (GEMMs) to trace the role of EMP in cancer progression, specifically the pancreatic epithelium conditional Kras/P53 mutant (PKCY) mice Lineage labelling of epithelial cells in this spontaneous PDAC model has allowed researchers to track these cells as they adopt mesenchymal properties and migrate away from the primary tumour into the circulation, seeding liver metastases [70]. In one study, EMP was detected in $42 \%$ of labelled PDAC epithelial cells, as assessed by the expression of EMP markers Zeb1 or Fsp1 and/or lack of E-cadherin. These cells were mostly observed in regions of inflammation, supporting the idea that EMP is driven by inflammatory interactions within the tissue microenvironment. Interestingly, some labelled epithelial cells that had undergone EMP displayed evidence of delamination and fibroblast morphology prior to tumour formation, and were otherwise indistinguishable from host stromal cells [70]. This is supportive of the very early, integral role that EMP may play in PanIN formation prior to tumour development.

Further studies in this same PDAC mouse model have shown that suppression of EMP via the knock-out of Twist1 or Snai1 TFs does not reduce metastasis, despite the decreased expression of EMP markers and increased cell proliferation as evidence for EMP ablation [71]. Equivalent numbers of lineage labelled epithelial cells were found in circulation and in metastases regardless of Twist/ Snai1 knockout, suggesting that other mechanisms are involved in PDAC cellular invasion. PDAC cells do not possess a strong epithelial phenotype however, and may thus be insensitive to the loss of Snail TFs, which are potent repressors of epithelial programs but are less efficient in inducing mesenchymal properties. This possibly explains why Snail is dispensable for EMP and metastatic progression in this model [71,72], and points towards alternative mechanisms of EMP induction that may be driving factors in this PDAC system.

Indeed, there is evidence that the Zeb1 TF is largely responsible for driving EMP in this GEMM model of PDAC development [73]. Zeb1 ablation in PDAC cells was not found to affect Twist1 expression, however it was associated with decreased Zeb2, Slug and a slight reduction in Snai1 expression. Zeb1 depleted tumours were better differentiated, indicating less local invasion, and showed significantly reduced metastasis when compared to control PDAC mice [73]. This is in direct contrast to depletion of Twist1 or Snai1, which did not affect metastasis in this model system, highlighting the importance of recognising the context and tissue specific drivers of EMP.

Subsequent investigations aimed at overcoming the limitations of identifying single EMP regulatory TFs has shown that lineage labelled cancer cells are able to metastasize without expression of $\alpha \mathrm{Sma}$ or Fsp1, both of which are thought to be robust markers of EMP activation in this model [74]. Indeed, larger metastatic nodules were found containing exclusively cells that had never expressed $\alpha$ Sma or Fsp1, while micrometastatic clusters of 3-5 cells were shown to have undergone EMP. Such evidence, combined with the fact that Zeb1 depletion in previous studies resulted in only a $50 \%$ reduction in metastasis underscores the pitfalls of seeking to identify individual master regulators and markers of such a complex process. Adding to this complexity, the emerging importance of hybrid EMP phenotypes, in which the expression of both epithelial and mesenchymal markers may occur at levels that are insufficient to drive the reporter constructs used in such lineage tracing models, adds a further technical challenge [75-77].

More recent attempts to understand EMP in individual PDAC cells has shown the activation of EMP transcriptional programs within certain subsets of tumour cell populations [14]. This study highlighted a clear role for cytokines from the stromal compartment in inducing EMP in certain PDAC cell lines, and indicated that EMP activation could be observed in discrete tumour gland subunits with prognostic utility. These models have provided considerable insights into the diverse mechanisms of PDAC development, and highlight that there are context-dependent EMP programs involved in both local invasion and metastatic dissemination that require further examination [72,78]. 


\section{In Vitro EMP Models and Exogenous Stimuli}

While GEMMS, in particular the PKCY model of spontaneous PDAC formation, are currently the gold standard for studies of the biology of EMP in tumourigenesis, in vitro studies form the basis for the majority of our current molecular understanding of intracellular events which occur in EMP. Many publicly available and in-house generated cell lines are used to study PDAC, but only a very limited number of these undergo well-characterised, stimulus-driven transitions that mimic the pathophysiological induction of EMP. This is perhaps consistent with the limited number of EMP events witnessed in in vivo models, highlighting the difficulties of studying such a dynamic process.

EMP is modulated by TGF $\beta$, receptor tyrosine kinases (RTK) ligands, WNT ligands, interleukins, hypoxia via HIF1 $\alpha$ signaling, as well as HIPPO, NOTCH signaling. Their mechanisms and specific impact on downstream EMP targets have been comprehensively reviewed elsewhere, however our understanding of their subtleties is on-going $[79,80]$. TGF $\beta$ acts as a tumour suppressor in normal tissue and early stage disease by regulating cell proliferation and inducing apoptosis through canonical signaling pathways, however this activity is lost as cellular transformation progresses [81-85]. Indeed, TGF $\beta$ is a potent activator of EMP in PDAC cells when its tumour suppressive signals are disrupted through SMAD4 mutations, found in 50\% of PDAC tumours [81,86]. Similarly, activating KRAS mutations found almost ubiquitously in PDAC cooperate with TGF $\beta$ signaling to hyperactivate downstream RAS/RAF MAPK pathways to induce EMP [87]. While TGFB activates the greatest number of EMP signaling pathways, and may thus be considered a major driver in PDAC, the activation of additional pathways shown in Figure 1 by RTK, WNT and interleukin ligands may provide additional layers of crosstalk. Activation of SMAD, MAPK, PI3K, STAT, and NFKB pathways are commonly demonstrated in PDAC EMP research, however the relative extent to which each pathway governs EMP is unclear, as many studies evaluate these pathways independently [29,88-94].

These complex pathways ultimately serve to influence transcriptional programs that co-operate directly and indirectly to control the plasticity that exists between epithelial and mesenchymal phenotypes of carcinoma cells (Figure 1). Of note is the increasing recognition for the role of long non-coding RNAs (LncRNA) and micro-RNAs (miRNA) in EMP regulation. Among the cells that do undergo EMP-like transitions, there is a degree of selectivity for the ligands that are able to activate these EMP programs, and this is reflected in the limited number of commercial cell lines that are commonly manipulated within the field. This is consistent with the level of heterogeneity reported in PDAC, and suggests discrete differences in steady state signaling, which may predispose a given cell's response or resistance to exogenous stimuli.

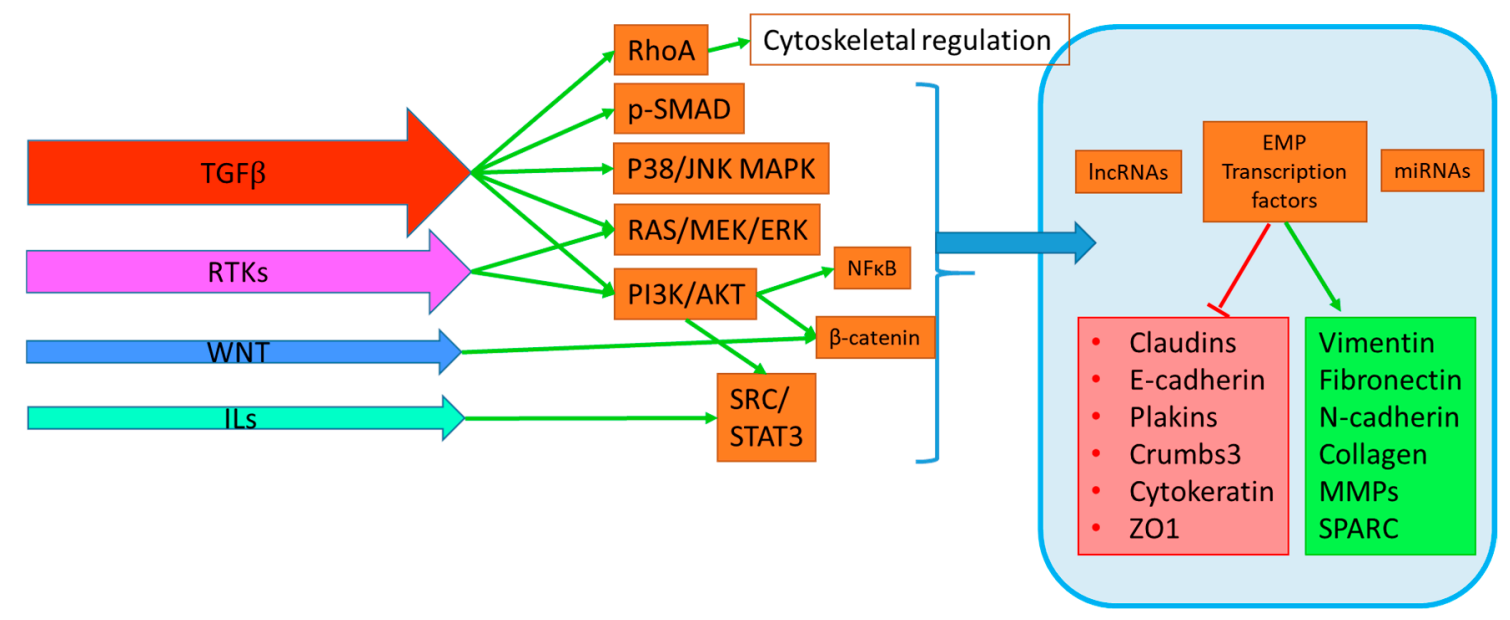

Figure 1. Simplified overview of cooperating signaling pathways in EMP. 
EMP is induced by stimuli shown within arrows on the left in order of potency. These signals activate signal transduction pathways that cooperate directly and indirectly to translocate signals to the nucleus (braced) to regulate EMP transcription factors, long non-coding RNAs (LncRNA), and micro RNAs (miRNAs).These factors then modulate EMP by discrete regulation of epithelial (Red Box) and mesenchymal (Green box) cellular properties, which in turn influence migration and invasion. Transforming growth factor (TGFB) activates the greatest number of these pathways, including direct cytoskeletal regulation by RhoA, aswell as canonical SMAD and non-canonical p38/JNK, MEK/ERK MAPK pathways and PI3K/AKT. Receptor tyrosine kinase (RTK) signaling is induced by binding of growth factor (GF) ligands such as EGF, IGF, FGF, HGF or VEGF and activates RAS/MEK/ERK, PI3K/AKT/NFKB and downstream SRC pathways. WNT signaling also modulates EMP by downstream stabilisation of B-catenin and subsequent nuclear translocation for EMP program activation by TCF/LEF transcription factors. Interleukins (ILs) can also induce EMP programs via STAT3 signaling. Additional mediators of EMP include Hypoxia, Hedgehog, Notch and Integrin signaling (not shown), and highlight the context dependent activation of EMP from micro-environmental cues.

While most studies rely upon knockdown and over-expression approaches to demonstrate the function of proteins in the context of cell migration, proliferation and EMP transitions, relatively few studies have investigated these targets in the context of the physiological induction of EMP in response to exogenous stimuli. Among PDAC cell lines, L3.6pl cells have been shown to respond to VEGF treatment [95], while the inflammatory cytokines TNF- $\alpha$ and IL-1 $\beta$ drive EMP in PaTu 8988T and AsPC-1 cells via Hedgehog signaling [96]. Collagen 1 also stimulated L3.6pl and BxPC-3 cells to become more invasive through interaction with DDR1 [97], and BMP2 was able to elicit a similar response in BxPC-3 cells [98]. PANC-1 cells are a well characterised model of inducible EMP, first shown by Ellenrieder et al to undergo a bidirectional change in response to TGF $\beta$ alongside CAPAN-1, COLO-357, IMIM-PC1 [99], HPAF-II, and CAPAN-2 cells [100]. PANC-1 cells have since been repeatedly modelled with regard to their EMP response, which has been shown to be inducible in response to TGF $\beta$, TNF- $\alpha$, HGF, or hypoxia through differing mechanisms [101-104]. SNAI1 appears to be a major driver in this model, being heavily regulated at the transcript and protein level, despite modest changes in E-cadherin and Vimentin proteins [105]. EMP is thus invariably the result of exogenous stimuli that activate discrete but conserved cellular pathways through novel intermediates that are an ongoing focus of basic cancer cell biology research.

\section{Pre-Clinical Discovery of EMP Targets}

As a result of the complexities of discerning cancer biology from native processes in vivo, the use of cell lines derived from primary tumours are a valuable means of modelling the molecular and phenotypic properties of cancers. Extensive investigation has been performed using gene silencing and overexpression approaches to evaluate the role that particular molecules have in regulating or effecting the EMP phenotypes of PDAC cells, however a concise summary of novel targets in the PDAC EMP field has to date been lacking. Thus, this review provides an exhaustive overview of such research as a platform for their integration, and progressive evaluation. The function of these candidate molecules can be broadly separated into secreted/soluble products (Table 1), receptors (Table 2), other membrane associated proteins (Table 3), cytoskeletal adaptors (Table 4), kinases (Table 5), intracellular mediators (Table 6), transcription factors (Table 7) and post transcriptional controllers (Table 8). The candidates shown were selected by searching Pubmed for the terms 'pancreatic' and 'epithelial', and articles investigating a novel candidate's impact on EMP phenotypes were manually curated. These effectors have been characterised to varying extents for their influence on invasion, migration, xenograft tumour growth, prognostic associations, and impact on known EMP signaling pathways. The proposed mechanisms of candidates and assays used to assess such effects are shown within tables and may be used to gauge where further support may be warranted to confirm and extend such findings. Due to the inherent variation in models used, the statistical power granted by IHC for varying sized patient cohorts with accompanying clinical information, and the level of EMP as a primary context, it is difficult 
to draw direct conclusions regarding pivotal significance within the field and clinical importance from such singular studies. Candidate expression in primary patient material that correlated with lymph-node metastasis are shown in bold within tables, and provide the best surrogate for their role in EMP mediated invasion, and include membrane bound proteins IGFBP2, ITGB4, CEACAM6 [106-108]. The use of IHC to capture dynamic EMP processes may be limited however, as shown in the case of LIN28B, where its expression is both induced by TGF $\beta$ and high in PDAC tissue, despite its role to suppress the pro-EMP non-coding RNA LET7a [109,110]. Such studies highlight both the utility and limitations of the links between in vitro assays and clinical material, and emphasise the need for both wider cohorts of patient material for validation and the development of GEMM models to strengthen findings in a standardized manner.

Figure 2 illustrates the proposed activity of some of these novel candidates, and how they may positively or negatively regulate discrete EMP signaling pathways. Of note are several candidates that converge to positively regulate EMP migratory phenotypes through FAK/Src and FAK/PI3K signaling, including the 5HT receptor and mucins, as well as EEF2K, USP22, and ZIP4. Their complete mechanisms of action and prevalence in PDAC tissue remain to be elucidated, however their inhibition may curb carcinoma invasion by blocking FAK activation and subsequent EMP modulation. Similarly, candidates participating in stability of EMP signaling and TF activity provide targets to modulate the EMP process specific for carcinoma cells. AURKA kinase has been shown to participate in a positive feedback loop with stabilization and activity of TWIST1, while PEAK1 and NES have been implicated in stabilization YAP/TAZ and SMAD TF activity. The discovery of discrete EMP regulation and development of combinatorial inhibitors may provide the opportunity for more personalized therapeutic approaches to curb metastatic disease.

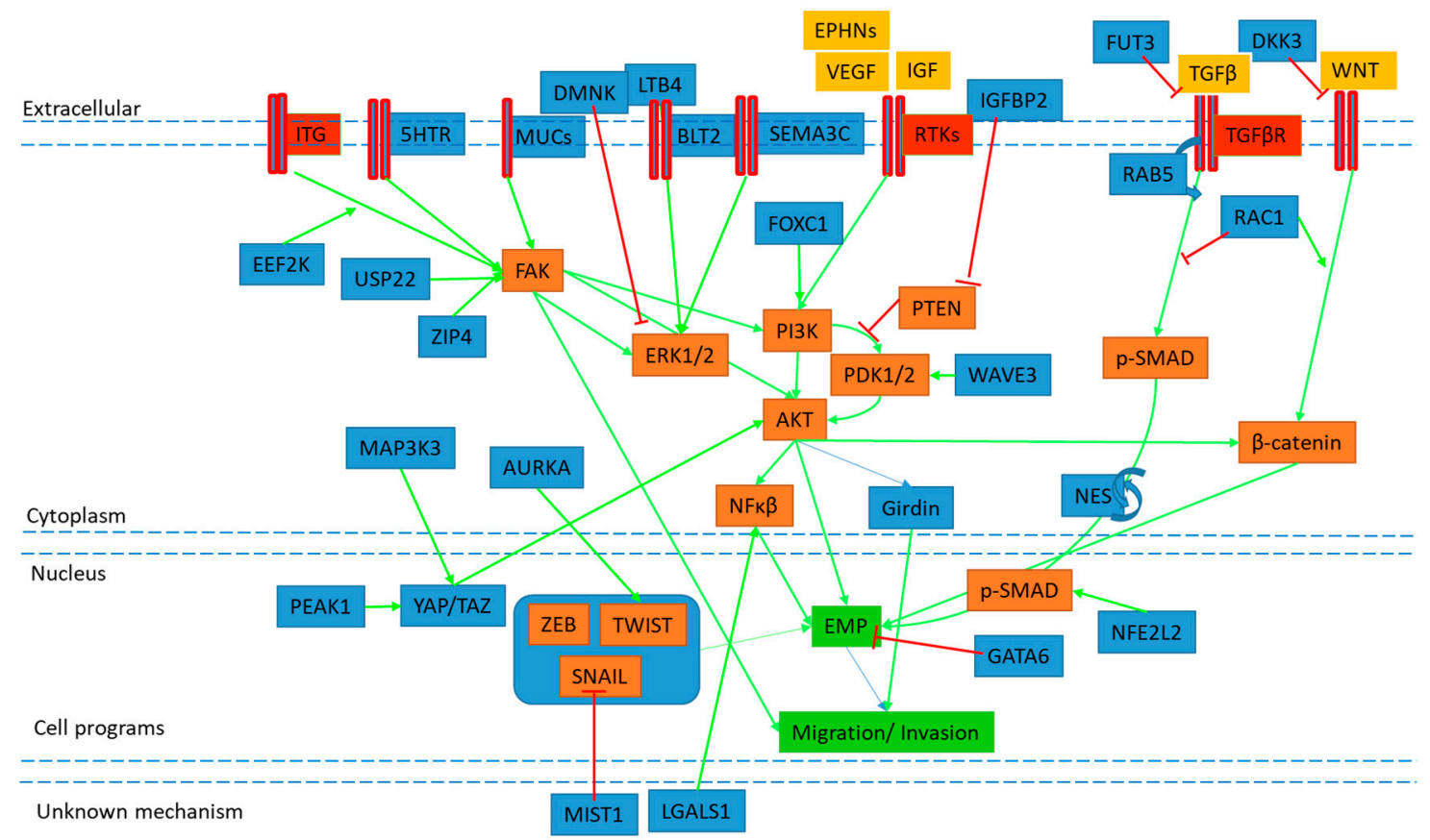

Figure 2. Simplified overview of the proposed mechanisms of novel candidates.

EMP and cell migration (GREEN boxes) is induced through cell surface proteins (ITG, 5HTR, MUC, BLT2, SEMA3C, RTK, TGF $\beta$ R) (RED) to activate signaling pathways (ORANGE boxes, blue arrows). These pathways are influenced by novel mediators (BLUE boxes) through activation (GREEN arrows) or inhibition (RED T) of known signaling members, however complete mechanisms of action remain to be elucidated. For full details, evidence of proposed mechanism and references of novel mediators, see tables below. Note signaling pathways shown have had intermediates removed for ease of visualisation. 
Table 1. Soluble and secreted factors that influence EMP. This table describes novel candidates that may be secreted within the ECM and act either directly through ligand-receptor interactions, or through mechanisms that remain to be demonstrated. Candidates that exhibit clinical correlation with lymph node metastasis are shown in bold.

\begin{tabular}{|c|c|c|c|c|c|c|c|c|}
\hline Cell Line & Target & $\begin{array}{l}\text { EMT } \\
\text { Regulation } \\
\text { (Direct or } \\
\text { Indirect } \\
\text { Observation) }\end{array}$ & KD/KO/Over-expression & Pathway/Mechanism & Functional Assay & $\begin{array}{l}\text { Human } \\
\text { Prognostic } \\
\text { Association }\end{array}$ & $\begin{array}{c}\text { EMT } \\
\text { Activator }\end{array}$ & Reference \\
\hline BxPC-3 & DKK3 & Negative, Direct & Over-expression & $\begin{array}{l}\text { DKK3 is overexpressed in } \\
\text { tumour and is antagonist of } \\
\text { WNT ligand activity, } \\
\text { preventing nuclear } \\
\text { translocation of } \beta \text {-catenin and } \\
\text { EMP under hypoxia }\end{array}$ & $\begin{array}{c}\text { Transwell assays, } \\
\text { chemo-resistance, IHC in } 75 \\
\text { matched PDAC v normal } \\
\text { samples, xenograft growth }\end{array}$ & Not performed & Hypoxia & [111] \\
\hline $\begin{array}{l}\text { ASPC-1, } \\
\text { PANC-1 }\end{array}$ & IGFBP2 & Positive, Direct & siRNA/Over-expression & $\begin{array}{l}\text { IGFBP2 activated NF-KB } \\
\text { through PI3K/AKT/IKK, } \\
\text { inhibited by PTEN }\end{array}$ & $\begin{array}{l}\text { WB, Transwell assays, } \\
\text { orthotopic growth, IHC in } \\
80 \text { patient PDAC and } \\
\text { lymph node samples }\end{array}$ & $\begin{array}{l}\text { Survival and } \\
\text { lymph node } \\
\text { metastasis }\end{array}$ & - & [106] \\
\hline PANC-1 & LTB4 & Positive, Direct & siRNA & $\begin{array}{l}\text { LTB4 induced EMT through } \\
\text { receptor BLT2 and ERK1/2 } \\
\text { activation }\end{array}$ & WB, Transwell assays & Not performed & LTB4 & [112] \\
\hline $\begin{array}{l}\text { Patu8988, } \\
\text { PANC-1 }\end{array}$ & DMKN & $\begin{array}{l}\text { Positive, } \\
\text { Indirect }\end{array}$ & shRNA & $\begin{array}{c}\text { Knockdown reduced p-STAT3 } \\
\text { and EMT increased ERK1/2, } \\
\text { AKT }\end{array}$ & $\begin{array}{l}\text { Proliferation, Transwell } \\
\text { assays, Xenograft, IHC in } \\
44 \text { patient PDAC tumours }\end{array}$ & $\begin{array}{l}\text { Correlated with } \\
\text { T stage }\end{array}$ & - & [113] \\
\hline PANC-1 & LGALS1 & Positive, Direct & shRNA/Over-expression & $\begin{array}{l}\text { LGALS1 IHC expression } \\
\text { correlated with MMP9 and } \\
\text { Vimentin in PDAC. PSC } \\
\text { LGALS1 promoted cancer cell } \\
\text { EMT and activation of NF-KB }\end{array}$ & $\begin{array}{c}\text { Xenograft, Proliferation, } \\
\text { Invasion, IHC in } 66 \text { PDAC } \\
\text { tumours }\end{array}$ & Not performed & & [114] \\
\hline $\begin{array}{l}\text { BxPC-3, } \\
\text { CFPAC }\end{array}$ & SEMA3C & $\begin{array}{l}\text { Positive, } \\
\text { Indirect }\end{array}$ & shRNA/Over-expression & $\begin{array}{l}\text { SEMA3C knockdown } \\
\text { suppressed EMT and } \\
\text { tumourigenesis, and activation } \\
\text { of ERK } 1 / 2 \text { signaling }\end{array}$ & $\begin{array}{l}\text { Proliferation, migration, } \\
\text { Scratch wound, Xenograft, } \\
\text { IHC in } 118 \text { PDAC tumours }\end{array}$ & $\begin{array}{l}\text { Stage, survival, } \\
\text { recurrence }\end{array}$ & & [115] \\
\hline Capan-1 & FUT3 & Positive, Direct & shRNA/Over-expression & $\begin{array}{c}\text { FUT3 knockdown impeded } \\
\text { proliferation, migration, } \\
\text { tumour growth and TGF } \beta \\
\text { induced EMT }\end{array}$ & $\begin{array}{c}\text { Proliferation, Scratch } \\
\text { wound, Transwell assays, } \\
\text { Xenograft }\end{array}$ & Not performed & TGF $\beta$ & [116] \\
\hline $\begin{array}{l}\text { PANC-1, } \\
\text { MIAPaCa-2, } \\
\text { Capan-2 }\end{array}$ & $\begin{array}{c}\text { MIF/ } \\
\text { NR3C2 }\end{array}$ & $\begin{array}{l}\text { Positive, } \\
\text { Indirect }\end{array}$ & siRNA/Over-expression & $\begin{array}{l}\text { MIF induces miR-301b, } \\
\text { targeting NR3C2, inducing } \\
\text { EMT and chemo sensitivity }\end{array}$ & $\begin{array}{l}\text { PDAC transcriptome by } \\
\text { array, IHC of } 173 \text { PDAC, } \\
\text { Proliferation, Colony } \\
\text { formation, Transwell } \\
\text { assays, chemo-resistance }\end{array}$ & $\begin{array}{c}\text { NR3C2 } \\
\text { inversely } \\
\text { prognostic by } \\
\text { RNA and IHC }\end{array}$ & - & [117] \\
\hline
\end{tabular}


Table 1. Cont.

\begin{tabular}{|c|c|c|c|c|c|c|c|c|}
\hline Cell Line & Target & $\begin{array}{c}\text { EMT } \\
\text { Regulation } \\
\text { (Direct or } \\
\text { Indirect } \\
\text { Observation) }\end{array}$ & KD/KO/Over-expression & Pathway/Mechanism & Functional Assay & $\begin{array}{l}\text { Human } \\
\text { Prognostic } \\
\text { Association }\end{array}$ & $\begin{array}{c}\text { EMT } \\
\text { Activator }\end{array}$ & Reference \\
\hline $\begin{array}{l}\text { PANC-1, } \\
\text { BxPC-3 }\end{array}$ & WNT5A & Positive, Direct & siRNA, Over-expression & $\begin{array}{l}\text { Wnt5a expression induced } \\
\text { EMT and invasion and was } \\
\text { elevated in PDAC by IHC }\end{array}$ & $\begin{array}{l}\text { Scratch wound, Transwell } \\
\text { assays, WB, orthotopic } \\
\text { growth, IHC of } 134 \text { PDAC } \\
\text { v normal }\end{array}$ & No & - & [118] \\
\hline PANC-1 & LCN2 & $\begin{array}{l}\text { Negative, } \\
\text { Indirect }\end{array}$ & Over-expression & $\begin{array}{l}\text { LCN2 expression correlated } \\
\text { with better survival and lower } \\
\text { EMT state }\end{array}$ & $\begin{array}{c}\text { IHC of } 60 \text { PDAC tumours, } \\
\text { Transwell assays }\end{array}$ & $\begin{array}{l}\text { Protective by } \\
\text { IHC }\end{array}$ & - & [119] \\
\hline $\begin{array}{l}\text { MIAPaca-2, } \\
\text { BxPC-3, } \\
\text { SUIT-2 }\end{array}$ & NOV & $\begin{array}{l}\text { Positive, } \\
\text { Indirect }\end{array}$ & shRNA/Over-expression & $\begin{array}{l}\text { NOV expression high in PDAC } \\
\text { by IHC, and induced EMT } \\
\text { phenotypes in vitro/in vivo }\end{array}$ & $\begin{array}{l}\text { Colony formation, soft agar, } \\
\text { Proliferation, Transwell } \\
\text { assays, in vivo metastasis }\end{array}$ & Not performed & - & [120] \\
\hline $\begin{array}{l}\text { PANC-1, } \\
\text { BxPC-3 }\end{array}$ & CCL18 & Positive, Direct & & $\begin{array}{l}\text { CCL18 expressed in } \\
\text { mesenchymal and cancer cells, } \\
\text { and induced EMT }\end{array}$ & $\begin{array}{l}\text { WB, Transwell assays, IHC } \\
\text { of } 62 \text { PDAC tumours, } \\
\text { serum ELISA from PDAC } \\
\text { patients }\end{array}$ & Survival & - & [121] \\
\hline $\begin{array}{l}\text { PANC-1, } \\
\text { BxPC-3 }\end{array}$ & TUFT1 & $\begin{array}{l}\text { Positive, } \\
\text { Indirect }\end{array}$ & siRNA/Over-expression & $\begin{array}{l}\text { TUFT1 expression correlated } \\
\text { with T stage and lymph node } \\
\text { metastasis by IHC, RNA } \\
\text { expression correlated with } \\
\text { HIF1a, SNAI1 and VIM }\end{array}$ & $\begin{array}{l}\text { WB, Proliferation, scratch } \\
\text { wound, Transwell assays, } \\
\text { Xenograft, IHC of } 63 \\
\text { PDAC tumours }\end{array}$ & $\begin{array}{l}\text { Yes in TCGA } \\
\text { by RNA }\end{array}$ & & [122] \\
\hline $\begin{array}{l}\text { SW1990, } \\
\text { ASPC-1 }\end{array}$ & OLR1 & Positive, Direct & siRNA/Over-expression & $\begin{array}{l}\text { OLR1 overexpressed in } \\
\text { tumours and correlates with } \\
\text { metastasis and poor survival, } \\
\text { overexpression induced EMT }\end{array}$ & $\begin{array}{c}\text { Transwell assays, scratch } \\
\text { wound, } \\
\text { Proliferation/apoptosis, } \\
\text { IHC of } 98 \text { PDAC tumours }\end{array}$ & $\begin{array}{l}\text { Yes survival by } \\
\text { IHC and TCGA }\end{array}$ & - & [123] \\
\hline $\begin{array}{l}\text { MIAPaCa-2, } \\
\text { PANC-1, } \\
\text { ASPC-1, } \\
\text { BxPC-3 }\end{array}$ & LOXL2 & $\begin{array}{l}\text { Positive, } \\
\text { Indirect }\end{array}$ & siRNA/Over-expression & $\begin{array}{c}\text { LOXL2 IHC expression } \\
\text { correlated with recurrence, } \\
\text { depth of invasion and poor } \\
\text { survival, and enhanced EMT } \\
\text { in vitro }\end{array}$ & $\begin{array}{c}\text { Transwell assays, IHC of } 80 \\
\text { PDAC tumours }\end{array}$ & Yes by IHC & - & [124] \\
\hline $\begin{array}{l}\text { PANC-1, } \\
\text { PK9 }\end{array}$ & TFF1 & Negative, Direct & siRNA & $\begin{array}{c}\text { TFF only expressed in PanIN } \\
\text { and intraductal neoplasia, not } \\
\text { normal or invasive PDAC, } \\
\text { knockdown activated EMT, } \\
\text { loss of TFF in GEMM drove } \\
\text { PanIN, PDAC and CAF } \\
\text { infiltration }\end{array}$ & $\begin{array}{c}\text { Transwell Invasion, Scratch } \\
\text { wound, KC GEMM, IHC on } \\
\text { small number of samples }\end{array}$ & Not performed & - & [125] \\
\hline
\end{tabular}


Table 2. Receptors. This table describes known receptors that may be activated to transduce signals required for EMP modulation. Candidates that exhibit clinical correlation with lymph node metastasis are shown in bold.

\begin{tabular}{|c|c|c|c|c|c|c|c|c|}
\hline Cell Line & Target & $\begin{array}{c}\text { EMT } \\
\text { Regulation }\end{array}$ & KD/KO/Over-expression & Pathway/Mechanism & Functional Assay & $\begin{array}{l}\text { Prognostic } \\
\text { Association }\end{array}$ & $\begin{array}{c}\text { EMT } \\
\text { Activator }\end{array}$ & Reference \\
\hline L3.6pl & $\begin{array}{l}\text { VEGFR1 } \\
\text { activation }\end{array}$ & Positive, Direct & & $\begin{array}{l}\text { RTK VEGFR-1 activation } \\
\text { induced SNAI1/2, TWIST }\end{array}$ & $\begin{array}{l}\text { E-cadherin/b-catenin } \\
\text { localization/WB }\end{array}$ & Not performed & VEGF & [95] \\
\hline $\begin{array}{l}\text { PANC-1, } \\
\text { MiaPaCa-2 }\end{array}$ & HTR1B, HTR1D & $\begin{array}{l}\text { Positive, } \\
\text { Indirect }\end{array}$ & siRNA & $\begin{array}{l}\text { 5-HT receptor knockdown } \\
\text { reduced uPAR and Src/FAK } \\
\text { signaling and EMT }\end{array}$ & $\begin{array}{l}\text { Scratch wound, } \\
\text { Transwell, Colony } \\
\text { formation }\end{array}$ & Not performed & - & [126] \\
\hline $\begin{array}{l}\text { PANC-1 } \\
\text { HPAC }\end{array}$ & IGF1R & $\begin{array}{l}\text { Positive, } \\
\text { Indirect }\end{array}$ & siRNA & $\begin{array}{l}\text { IGF1R overexpressed in } \\
\text { PDAC by IHC, silencing } \\
\text { inhibits AKT/PI3K, MAPK, } \\
\text { JAK/STAT signaling } \\
\text { pathways }\end{array}$ & $\begin{array}{l}\text { Transwell assays, } \\
\text { soft agar, } \\
\text { Proliferation, } \\
\text { apoptosis, IHC of } \\
\text { TMA }\end{array}$ & Not performed & - & [127] \\
\hline $\begin{array}{l}\text { L3.6pl, } \\
\text { BxPC-3 }\end{array}$ & DDR1 & Positive, Direct & siRNA/ Over-expression & $\begin{array}{l}\text { DDR1 expression correlates } \\
\text { with CHD2 expression by } \\
\text { IHC, DDR1-b signals through } \\
\text { SHC1 adapter to PYK2 to } \\
\text { induce CDH2 }\end{array}$ & $\begin{array}{l}\text { Invasion, IHC of } \\
\text { PDAC TMA }\end{array}$ & Not performed & COL1A & [97] \\
\hline PANC-1 & $\mathrm{SMO}$ & $\begin{array}{l}\text { Positive, } \\
\text { Indirect }\end{array}$ & siRNA & $\begin{array}{l}\text { Hedgehog activated in } \\
\text { tumourspheres, SMO } \\
\text { knockdown inhibited } \\
\text { CSC/EMT features properties }\end{array}$ & $\begin{array}{c}\text { Proliferation, } \\
\text { sphere formation, } \\
\text { Transwell assays, } \\
\text { Xenograft }\end{array}$ & Not performed & - & [128] \\
\hline $\begin{array}{l}\text { PANC-1, } \\
\text { BxPC-3 }\end{array}$ & EPHA4 & Positive, Direct & siRNA & $\begin{array}{c}\text { EPHA4 knockdown } \\
\text { suppressed EMT, MMP2 } \\
\text { activity }\end{array}$ & $\begin{array}{c}\text { Gelatin } \\
\text { zymography, } \\
\text { Transwell assays, } \\
\text { scratch wound, WB }\end{array}$ & Not performed & - & [129] \\
\hline $\begin{array}{l}\text { CFPAC-1, } \\
\text { AsPC-1 }\end{array}$ & ITGB4 & Positive, Direct & siRNA/Over-expression & $\begin{array}{c}\text { ITGB4 IHC expression } \\
\text { correlated with T stage, } \\
\text { knockdown inhibited EMP }\end{array}$ & $\begin{array}{l}\text { Transwell assays, } \\
\text { WB, IHC of } 134 \\
\text { PDAC tumours }\end{array}$ & $\begin{array}{l}\text { Survival lymph } \\
\text { node } \\
\text { metastasis by } \\
\text { IHC }\end{array}$ & TGF $\beta$ & [107] \\
\hline $\begin{array}{l}\text { PANC-1, } \\
\text { MiaPaCa2, } \\
\text { Capan2 }\end{array}$ & $\mathrm{F} 2 \mathrm{R}$ & $\begin{array}{l}\text { Positive, } \\
\text { Indirect }\end{array}$ & shRNA & $\begin{array}{c}\text { F2R (PAR1) expression } \\
\text { associated with } \\
\text { mesenchymal gene signature }\end{array}$ & $\begin{array}{l}\text { Xenograft, Scratch } \\
\text { wound }\end{array}$ & Not performed & - & [130] \\
\hline
\end{tabular}


Table 3. Membrane associated proteins. This table describes membrane bound proteins that may interact with other cells and the extracellular environment to sense cues that modulate EMP in a context dependent fashion. Candidates that exhibit clinical correlation with lymph node metastasis are shown in bold.

\begin{tabular}{|c|c|c|c|c|c|c|c|c|}
\hline Cell Line & Target & $\begin{array}{c}\text { EMT } \\
\text { Regulation }\end{array}$ & KD/KO/Over-expression & Pathway/Mechanism & Functional Assay & $\begin{array}{c}\text { Prognostic } \\
\text { Association }\end{array}$ & $\begin{array}{c}\text { EMT } \\
\text { Activator }\end{array}$ & Reference \\
\hline PANC-1 & CDCP1 & $\begin{array}{l}\text { Positive, } \\
\text { Indirect }\end{array}$ & siRNA & $\begin{array}{l}\text { CDCP1 expression high } \\
\text { in PDAC, induced by } \\
\text { BMP4/ERK signaling, } \\
\text { and knockdown inhibited } \\
\text { EMT phenotypes }\end{array}$ & $\begin{array}{c}\text { Scratch wound, } \\
\text { Transwell, spheroid } \\
\text { formation, } \\
\text { chemo-resistance, } \\
\text { IHC on } 42 \text { PDAC } \\
\text { tumours }\end{array}$ & Not performed & - & [131] \\
\hline $\begin{array}{l}\text { Colo-357, } \\
\text { Capan-1 }\end{array}$ & MUC16 & $\begin{array}{l}\text { Positive, } \\
\text { Indirect }\end{array}$ & siRNA, CRISPR/Cas9 & $\begin{array}{c}\text { MUC16 knockdown } \\
\text { decreased FAK mediated } \\
\text { AKT/ERK/MAPK } \\
\text { activation, and EMT }\end{array}$ & $\begin{array}{l}\text { Proliferation, } \\
\text { migration, Colony } \\
\text { formation, } \\
\text { Xenograft }\end{array}$ & Not performed & - & [132] \\
\hline $\mathrm{MiaPaCa} 2$ & ANXA1 & $\begin{array}{l}\text { Positive, } \\
\text { Indirect }\end{array}$ & CRISPR & $\begin{array}{l}\text { ANXA1 KO } \\
\text { downregulated miR196a, } \\
\text { effected cell motility and } \\
\text { liver metastases in vivo }\end{array}$ & $\begin{array}{l}\text { Scratch wound, } \\
\text { Transwell } \\
\text { migration, Invasion, } \\
\text { Xenograft }\end{array}$ & Not performed & & {$[133,134]$} \\
\hline $\begin{array}{l}\text { CFPAC-1, } \\
\text { PANC-1 }\end{array}$ & CEACAM6 & Positive, Direct & $\begin{array}{l}\text { shRNA, } \\
\text { Over-expression }\end{array}$ & $\begin{array}{l}\text { CEACAM6, regulated } \\
\text { by } \mathrm{miR}-29 \mathrm{a} / \mathrm{b} / \mathrm{c} \\
\text { required for EMT }\end{array}$ & $\begin{array}{c}\text { Transwell assays, } \\
\text { Xenograft, WB, } \\
\text { IHC in } 99 \text { PDAC } \\
\text { tumours }\end{array}$ & $\begin{array}{l}\text { Lymph node } \\
\text { metastasis }\end{array}$ & - & [108] \\
\hline $\begin{array}{l}\text { SUIT-2, } \\
\text { CAPAN-2 }\end{array}$ & TM4SF1 & $\begin{array}{l}\text { Negative, } \\
\text { Indirect }\end{array}$ & siRNA & $\begin{array}{l}\text { TM4SF1 IHC expression } \\
\text { protective, knockdown } \\
\text { induced migration and } \\
\text { decreased E-cadherin }\end{array}$ & $\begin{array}{l}\text { Transwell assays, } \\
\text { IHC in } 74 \text { PDAC } \\
\text { tumours }\end{array}$ & $\begin{array}{l}\text { Yes inversely } \\
\text { prognostic by } \\
\text { IHC }\end{array}$ & TGF $\beta$ & [135] \\
\hline $\begin{array}{l}\text { PANC-1, } \\
\text { SW1990 }\end{array}$ & DPP4 & $\begin{array}{l}\text { Positive, } \\
\text { Indirect }\end{array}$ & siRNA/ Over-expression & $\begin{array}{l}\text { DPP4 (CD26) knockdown } \\
\text { suppressed EMT, in vivo } \\
\text { growth }\end{array}$ & $\begin{array}{l}\text { Proliferation, } \\
\text { Transwell assays, } \\
\text { Xenograft, WB }\end{array}$ & Not performed & - & [136] \\
\hline $\begin{array}{l}\text { PANC-1, } \\
\text { AsPC-1 }\end{array}$ & SLC39A4 & $\begin{array}{l}\text { Positive, } \\
\text { Indirect }\end{array}$ & siRNA/ overexpression & $\begin{array}{l}\text { SLC39A4 (ZIP4) IHC } \\
\text { expression correlated } \\
\text { with ZEB1 and EMT, } \\
\text { increasing FAK and } \\
\text { paxillin phosphorylation }\end{array}$ & $\begin{array}{l}\text { Xenograft, Scratch } \\
\text { wound, Transwell } \\
\text { migration, Invasion, } \\
\text { IHC of } 72 \text { paired } \\
\text { PDAC v normal }\end{array}$ & Not performed & - & [137] \\
\hline
\end{tabular}


Table 4. Cytoskeletal adaptors. This table describes intracellular adapter proteins that may participate in and be required protein complex localization and transduction of signals that modulate EMP. Candidates that exhibit clinical correlation with lymph node metastasis are shown in bold.

\begin{tabular}{|c|c|c|c|c|c|c|c|c|}
\hline Cell Line & Target & $\begin{array}{c}\text { EMT } \\
\text { Regulation }\end{array}$ & KD/KO/Over-expression & Pathway/Mechanism & Functional Assay & $\begin{array}{c}\text { Prognostic } \\
\text { Association }\end{array}$ & $\begin{array}{c}\text { EMT } \\
\text { Activator }\end{array}$ & Reference \\
\hline $\begin{array}{l}\text { PANC-1, } \\
\text { CFPAC-1 }\end{array}$ & WASF3 & $\begin{array}{l}\text { Positive, } \\
\text { Indirect }\end{array}$ & siRNA, & $\begin{array}{c}\text { WASF3 (WAVE3) } \\
\text { knockdown suppressed } \\
\text { PDK2, downregulating } \\
\text { PBK/AKT pathway and } \\
\text { EMT }\end{array}$ & $\begin{array}{c}\text { Proliferation, } \\
\text { migration, } \\
\text { Invasion, Scratch } \\
\text { wound, IHC of } 87 \\
\text { paired PDAC v } \\
\text { normal }\end{array}$ & $\begin{array}{l}\text { Lymph node } \\
\text { metastasis }\end{array}$ & - & [138] \\
\hline $\begin{array}{l}\text { PANC-1, } \\
\text { AsPC-1, } \\
\text { MiaPaCa-2 }\end{array}$ & NES & Positive, Direct & shRNA/Over-expression & $\begin{array}{l}\text { NES (Nestin) required for } \\
\text { EMT and induced by } \\
\text { TGF } \beta \text { in positive feedback } \\
\text { loop promoting p-smad2 }\end{array}$ & $\begin{array}{c}\text { Xenograft, } \\
\text { Transwell assays, } \\
\text { IHC of GEMM }\end{array}$ & Not performed & TGF $\beta$ & {$[139,140]$} \\
\hline $\begin{array}{l}\text { HPAF-II, } \\
\text { PANC-04.03 } \\
\text { PANC-1 }\end{array}$ & DNM2 & $\begin{array}{l}\text { Positive, } \\
\text { Indirect }\end{array}$ & siRNA, Over-expression & $\begin{array}{l}\text { Upregulated by IHC in } \\
\text { PDAC, DNM2/VAV1 } \\
\text { interaction required for } \\
\text { RAC-1 induced } \\
\text { lamellipodia formation }\end{array}$ & $\begin{array}{l}\text { Transwell assays, } \\
\text { lamellipodia } \\
\text { formation, } \\
\text { xenograft, IHC of } 85 \\
\text { PDAC tumours }\end{array}$ & Not performed & $\begin{array}{c}\text { EGF } \\
\text { (HPAF-II) }\end{array}$ & {$[141,142]$} \\
\hline SUIT-2 & RAB5A & $\begin{array}{l}\text { Positive, } \\
\text { Indirect }\end{array}$ & siRNA & $\begin{array}{l}\text { RAB5 IHC expression } \\
\text { correlated with invasion } \\
\text { and CDH1, aids TGF } \beta R \\
\text { endocytosis, stimulates } \\
\text { FA turnover, prognostic } \\
\text { in PDAC, breast, ovarian }\end{array}$ & $\begin{array}{c}\text { Morphology, } \\
\text { Proliferation, } \\
\text { Transwell assays, } \\
\text { IHC of } 111 \text { PDAC } \\
\text { tumours }\end{array}$ & Survival IHC & - & [143] \\
\hline
\end{tabular}


Table 5. Kinases and Phosphatases. This table describes proteins with activity that may directly participate in signal transduction by phospho-regulation of intracellular substrates. Candidates that exhibit clinical correlation with lymph node metastasis are shown in bold.

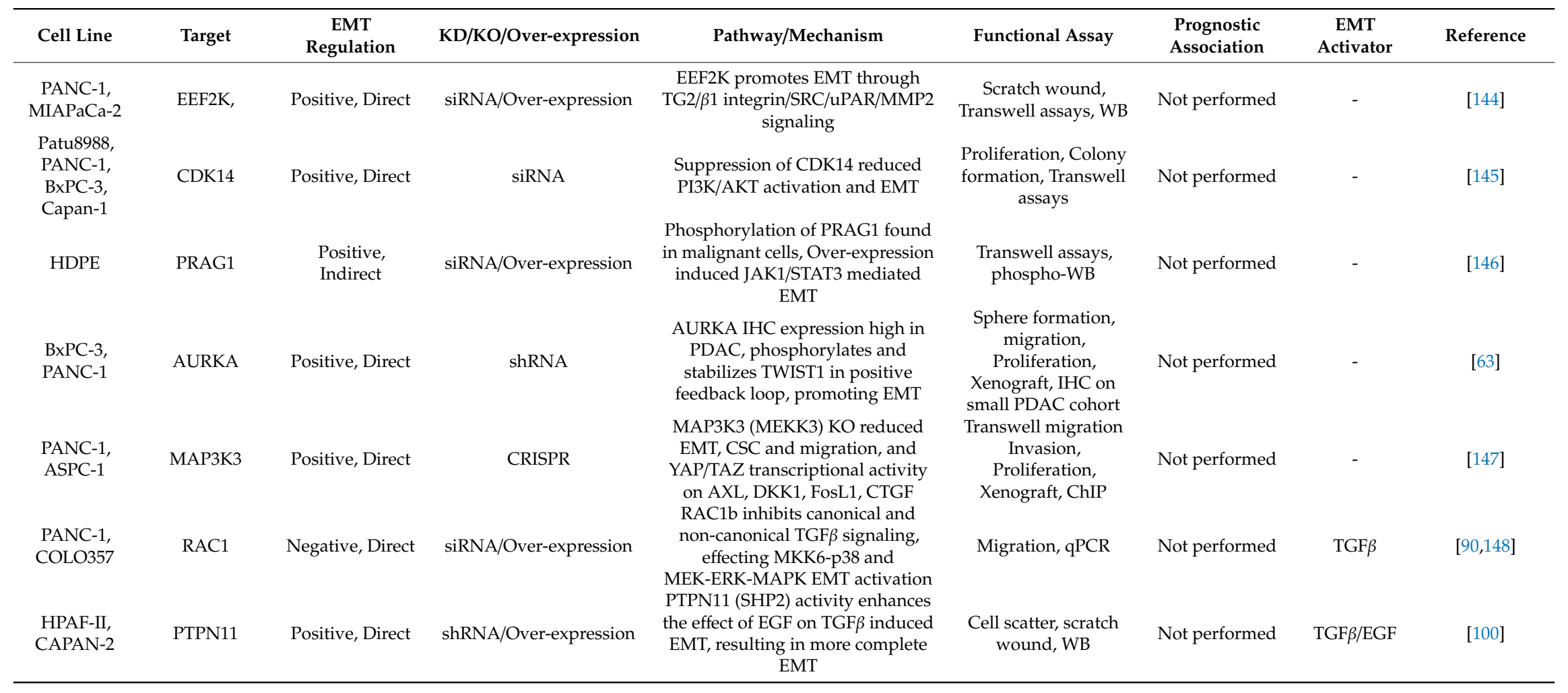


Table 6. Enzymes and Co-factors. This table describes intracellular proteins that may directly or indirectly participate in pathways required for EMP modulation by other enzymatic control of substrate proteins. Candidates that exhibit clinical correlation with lymph node metastasis are shown in bold.

\begin{tabular}{|c|c|c|c|c|c|c|c|c|}
\hline Cell Line & Target & $\begin{array}{c}\text { EMT } \\
\text { Regulation }\end{array}$ & KD/KO/Over-expression & Pathway/Mechanism & Functional Assay & $\begin{array}{c}\text { Prognostic } \\
\text { Association }\end{array}$ & $\begin{array}{c}\text { EMT } \\
\text { Activator }\end{array}$ & Reference \\
\hline PANC-1 & USP22 & Positive, Direct & shRNA/Over-expression & $\begin{array}{c}\text { USP22 expression correlated with } \\
\text { Ezrin and FAK phosphorylation } \\
\text { and EMT }\end{array}$ & $\begin{array}{l}\text { Scratch wound, Transwell } \\
\text { assays, WB }\end{array}$ & Not performed & - & [149] \\
\hline $\begin{array}{l}\text { 779E, } 1334 \\
\text { PDCL }\end{array}$ & EIF5A & $\begin{array}{l}\text { Positive, } \\
\text { Indirect }\end{array}$ & shRNA/Over-expression & $\begin{array}{l}\text { Mutant KRAS induces EIF5A, } \\
\text { stimulating PEAK1 mediated ECM } \\
\text { signaling. PEAK1 binds YAP/TAZ } \\
\text { driving stem TFs }\end{array}$ & Sphere formation, IP, WB & Not performed & - & [150] \\
\hline $\begin{array}{l}\text { AsPC-1, } \\
\text { PANC-1 }\end{array}$ & EIF4E & $\begin{array}{l}\text { Negative, } \\
\text { Indirect }\end{array}$ & siRNA & $\begin{array}{l}\text { Knockdown of MNK effector, } \\
\text { EIF4E, induced ZEB1 through } \\
\text { repression of miR-200c, miR-141, } \\
\text { MNK inhibitors induce MET }\end{array}$ & Collagen 3D, qPCR & Not performed & - & [94] \\
\hline BxPC-3 & RGCC & Positive, Direct & siRNA & $\begin{array}{l}\text { RGCC regulated by HIF1 } \alpha \text { and } \\
\text { required for hypoxia induced EMT }\end{array}$ & qPCR, WB & Not performed & hypoxia & [151] \\
\hline $\begin{array}{l}\text { PANC-1 } \\
\text { MIA PaCa-2 }\end{array}$ & SET & Positive, Direct & shRNA/ Over-expression & $\begin{array}{l}\text { SET over-expression activated } \\
\text { Rac1/JNK/c-Jun pathway and } \\
\text { decreased PP2A activity, } \\
\text { N-cadherin and EMT TFs up }\end{array}$ & $\begin{array}{l}\text { Transwell assays, Colony } \\
\text { formation, Xenograft } \\
\text { tumour growth and liver } \\
\text { metastases }\end{array}$ & Not performed & - & [152] \\
\hline $\begin{array}{l}\text { MiaPaCa2, } \\
\text { SW1990, } \\
\text { PANC-1, } \\
\text { CFPAC1 }\end{array}$ & GPX1 & Negative, Direct & shRNA/Over-expression & $\begin{array}{l}\text { GPX1 IHC expression lower in } \\
\text { PDAC, silencing induced EMT and } \\
\text { gemcitabine resistance through } \\
\text { ROS activated } \\
\text { PI3K/Akt/GSK3B/SNAIL, } \\
\text { Over-expression sensitized in vivo }\end{array}$ & $\begin{array}{l}\text { Transwell migration, } \\
\text { chemo-resistance, } \\
\text { Xenografts, IHC of } 281 \\
\text { PDAC tumours, and } 42 \\
\text { paired PDAC v normal }\end{array}$ & $\begin{array}{l}\text { Yes inversely } \\
\text { prognostic by } \\
\text { IHC }\end{array}$ & & [153] \\
\hline $\begin{array}{l}\text { BxPC-3, } \\
\text { PANC-1, } \\
\text { MiaPaCa2, } \\
\text { PSN1 }\end{array}$ & HDAC1 & $\begin{array}{l}\text { Positive, } \\
\text { Indirect }\end{array}$ & siRNA & $\begin{array}{l}\text { HDAC IHC expression and activity } \\
\text { correlated with EMT phenotype }\end{array}$ & $\begin{array}{l}\text { IHC, Transwell Invasion, } \\
\text { IHC of } 103 \text { PDAC } \\
\text { tumours }\end{array}$ & Survival by IHC & - & [154] \\
\hline $\begin{array}{l}\text { PANC-1 } \\
\text { BxPC-3 }\end{array}$ & Class I HDAC & $\begin{array}{l}\text { Positive, } \\
\text { Indirect }\end{array}$ & 4SC-202 small inhibitor & $\begin{array}{l}\text { HDACi (inhibition) blocked TGF } \beta \\
\text { induced EMT in PANC-1, } \\
\text { requiring BRD4 and MYC for effect } \\
\text { of HDACi }\end{array}$ & $\begin{array}{l}\text { Migration, sphere } \\
\text { formation, Xenograft }\end{array}$ & Not performed & $\begin{array}{c}\text { TGF } \beta \\
\text { (PANC-1) }\end{array}$ & [155] \\
\hline $\begin{array}{l}\text { CFPAC-1, } \\
\text { L3.7-2 }\end{array}$ & PAFAH1B2 & Positive, Direct & siRNA/Over-expression & $\begin{array}{l}\text { PAFAH1B2 IHC expression higher } \\
\text { in PDAC, HIF1a expression } \\
\text { regulated PAFAH1B2 via direct } \\
\text { promoter binding }\end{array}$ & $\begin{array}{c}\text { Transwell migration, } \\
\text { Invasion, orthotopic } \\
\text { Xenograft/ liver } \\
\text { metastases, } \\
\text { HIF1a/PAFAH1B2 } \\
\text { co-localization in PDAC, } \\
\text { IHC of } 124 \text { PDAC } \\
\text { tumours and } 70 \text { normal }\end{array}$ & $\begin{array}{l}\text { Survival by IHC } \\
\text { and TCGA }\end{array}$ & hypoxia & [156] \\
\hline
\end{tabular}


Table 6. Cont

\begin{tabular}{|c|c|c|c|c|c|c|c|c|}
\hline Cell Line & Target & $\begin{array}{c}\text { EMT } \\
\text { Regulation }\end{array}$ & KD/KO/Over-expression & Pathway/Mechanism & Functional Assay & $\begin{array}{l}\text { Prognostic } \\
\text { Association }\end{array}$ & $\begin{array}{c}\text { EMT } \\
\text { Activator }\end{array}$ & Reference \\
\hline $\begin{array}{l}\text { PANC-1, } \\
\text { MIAPaCa-2 }\end{array}$ & KDM4B & Positive, Direct & siRNA & $\begin{array}{c}\text { KDM4B IHC expression } \\
\text { correlated with ZEB1 in } \\
\text { PDAC, knockdown inhibited } \\
\text { TGF } \beta \text { induced EMT in } \\
\text { PANC-1 by regulating ZEB1 } \\
\text { methylation }\end{array}$ & $\begin{array}{l}\text { CHIP, scratch wound, } \\
\text { Transwell assays, IHC of } \\
49 \text { PDAC tumours }\end{array}$ & Not performed & TGF $\beta$ & [157] \\
\hline $\begin{array}{l}\text { HPAC, } \\
\text { BxPC-3, } \\
\text { Colo357 } \\
\text { PANC-1, } \\
\text { MiaPaCa-2 }\end{array}$ & SMURF2 & Negative, Direct & & $\begin{array}{l}\text { SMURF negative regulator of } \\
\text { TGF } \beta \text { induced EMT, } \\
\text { suppressed by miR-15b }\end{array}$ & $\begin{array}{c}\text { Scratch wound, Transwell } \\
\text { assays, WB }\end{array}$ & Not performed & TGF $\beta$ & [158] \\
\hline $\begin{array}{l}\text { CAPAN-1 } \\
\text { PANC-1 }\end{array}$ & CUL4B & Positive, Direct & miRNA & $\begin{array}{c}\text { CUL4B IHC expression } \\
\text { higher in PDAC, regulated } \\
\text { by miR -300, required for } \\
\text { Wnt } / \beta \text {-catenin induced EMP } \\
\text { KMT5C (SUV420H2) }\end{array}$ & $\begin{array}{l}\text { qPCR, Transwell assays, } \\
\text { Xenograft, IHC of } 110 \\
\text { PDAC v normal }\end{array}$ & Not performed & - & [159] \\
\hline PANC-1 & KMT5C & Positive, Direct & siRNA & $\begin{array}{l}\text { expression higher in PanIN } \\
\text { and PDAC, methylates } \\
\text { H4K20me3,suppresses } \\
\text { epithelial drivers FOXA1, } \\
\text { OVOL2, OVOL2 }\end{array}$ & $\begin{array}{c}\text { Transwell assays, } \\
\text { chemo-resistance, sphere } \\
\text { formation, }\end{array}$ & Not performed & - & [160] \\
\hline PANC-1 & NOX4 & Positive, Direct & siRNA & $\begin{array}{c}\text { NOX4 IHC expression } \\
\text { elevated in PDAC, aids ROS } \\
\text { generation and TGF } \beta \\
\text { induced EMT }\end{array}$ & Transwell assays, WB & Not performed & TGF $\beta$ & [161] \\
\hline BxPC-3 & PAWR & $\begin{array}{l}\text { Negative, } \\
\text { Indirect }\end{array}$ & siRNA, Over-expression & $\begin{array}{l}\text { PAWR (PAR4) suppressed in } \\
\text { cisplatin resistant EMT cells, } \\
\text { required PI3K/AKT signaling }\end{array}$ & $\begin{array}{c}\text { Transwell assays, } \\
\text { Proliferation, WB, } \\
\text { Xenograft }\end{array}$ & Not performed & - & [162] \\
\hline BxPC-3 & PPM1H & $\begin{array}{l}\text { Negative, } \\
\text { Indirect }\end{array}$ & siRNA & $\begin{array}{l}\text { PPM1H expression decreased } \\
\text { by TGF } \beta / \text { BMP2 treatment, } \\
\text { knockdown induced EMT }\end{array}$ & $\begin{array}{l}\text { Proliferation, Transwell } \\
\text { assays, WB, apoptosis }\end{array}$ & Not performed & TGF $\beta$, BMP2 & [98] \\
\hline PANC-1 & HMGN5 & $\begin{array}{l}\text { Positive, } \\
\text { Indirect }\end{array}$ & shRNA & $\begin{array}{c}\text { HMNG5 silencing reduced } \\
\text { Wnt expression } \\
\text { GOLM1 }\end{array}$ & $\begin{array}{c}\text { Xenograft, Transwell } \\
\text { migration Invasion, WB, }\end{array}$ & Not performed & - & [163] \\
\hline PANC-1 & GOLM1 & Positive, Direct & siRNA/ overexpression & $\begin{array}{l}\text { overexpression induced } \\
\text { EMT and correlated with } \\
\text { human metastasis and } \\
\text { Xenograft growth }\end{array}$ & $\begin{array}{l}\text { Xenograft, Transwell } \\
\text { migration Invasion, } \\
\text { Scratch wound, WB }\end{array}$ & Not performed & - & [164] \\
\hline
\end{tabular}


Table 7. Transcription Factors and Cofactors. This table describes transcription factors and cofactors that influence gene expression required for actions of EMP in their respective systems. Candidates that exhibit clinical correlation with lymph node metastasis are shown in bold.

\begin{tabular}{|c|c|c|c|c|c|c|c|c|}
\hline Cell Line & Target & $\begin{array}{c}\text { EMT } \\
\text { Regulation }\end{array}$ & KD/KO/Over-expression & Pathway/Mechanism & Functional Assay & $\begin{array}{l}\text { Prognostic } \\
\text { Association }\end{array}$ & $\begin{array}{c}\text { EMT } \\
\text { Activator }\end{array}$ & Reference \\
\hline $\begin{array}{l}\text { PaTu 8988T, } \\
\text { AsPC-1 }\end{array}$ & GLI1 & Positive, Direct & siRNA & $\begin{array}{l}\text { GLI1 component of HH } \\
\text { signaling, induced EMT } \\
\text { by TNF- } \alpha / \text { IL-1 } \beta \text {, } \\
\text { mediated through NF-кB } \\
\text { pathway }\end{array}$ & Transwell assays, WB & Not performed & TNF- $\alpha / \mathrm{IL}-1 \beta$ & {$[96,165-168]$} \\
\hline $\begin{array}{l}\text { Colo-357, } \\
\text { L3.7 }\end{array}$ & FOXM1 & $\begin{array}{l}\text { Positive, } \\
\text { Indirect }\end{array}$ & siRNA/Over-expression & $\begin{array}{l}\text { FOXM1c activates uPAR } \\
\text { promoter directly, } \\
\text { inducing EMT }\end{array}$ & $\begin{array}{c}\text { Scratch wound, } \\
\text { Transwell migration, } \\
\text { IHC of PDAC TMA v } \\
\text { normal }\end{array}$ & $\begin{array}{l}\text { Elevated in } \\
\text { metastatic } \\
\text { PDAC }\end{array}$ & - & [169] \\
\hline $\begin{array}{l}\text { BxPC-3, } \\
\text { ASPC-1, } \\
\text { PANC-1 }\end{array}$ & TAZ & Negative, Direct & shRNA, Over-expression & $\begin{array}{l}\text { TAZ required for EMT } \\
\text { through TEA/ATTS TFs, } \\
\text { activation correlates with } \\
\text { suppression of NF2 }\end{array}$ & $\begin{array}{l}\text { Colony formation, } \\
\text { Xenograft, Transwell } \\
\text { assays, IHC of } 57 \\
\text { PDAC v normal }\end{array}$ & $\begin{array}{l}\text { Correlated with } \\
\text { PDAC } \\
\text { differentiation }\end{array}$ & - & [170] \\
\hline $\begin{array}{l}\text { PANC-1, } \\
\text { CAPAN-1 }\end{array}$ & YAP & Positive, Direct & shRNA/Over-expression & $\begin{array}{c}\text { YAP expression } \\
\text { associated with activation } \\
\text { of AKT cascade and EMT }\end{array}$ & $\begin{array}{c}\text { Transwell assays, } \\
\text { chemo-resistance, WB }\end{array}$ & Not performed & - & [171] \\
\hline $\begin{array}{l}\text { PANC-1, } \\
\text { BxPC-3 }\end{array}$ & HSF1 & $\begin{array}{l}\text { Positive, } \\
\text { Indirect }\end{array}$ & siRNA & $\begin{array}{c}\text { p-HSF1 IHC elevated in } \\
\text { PDAC, promotes } \\
\text { invasion and is } \\
\text { downregulated by } \\
\text { p-AMPK }\end{array}$ & $\begin{array}{c}\text { Transwell assays, } \\
\text { scratch, WB, GEMM }\end{array}$ & Not performed & - & [172] \\
\hline $\begin{array}{c}\text { HPAC, } \\
\text { MiaPaCa2 }\end{array}$ & FOXC1 & $\begin{array}{l}\text { Positive, } \\
\text { Indirect }\end{array}$ & siRNA/Over-expression & $\begin{array}{l}\text { IGFR1 positively } \\
\text { regulates FOXC1, } \\
\text { activating PI3K/Akt/ERK, } \\
\text { promoting migration, and } \\
\text { EMT, and tumour growth }\end{array}$ & $\begin{array}{l}\text { Xenograft, Transwell } \\
\text { migration Invasion, } \\
\text { soft agar }\end{array}$ & Not performed & IGF & [173] \\
\hline $\begin{array}{l}\text { PANC-1, } \\
\text { SW1990 }\end{array}$ & $\begin{array}{l}\text { BHLHA15, } \\
\text { Direct }\end{array}$ & Negative, Direct & Over-expression & $\begin{array}{l}\text { BHLHA15 (MIST1) } \\
\text { Over-expression } \\
\text { suppressed tumour } \\
\text { growth \& metastases. } \\
\text { Caused MET by } \\
\text { suppressing SNAIL } \\
\text { indirectly }\end{array}$ & $\begin{array}{l}\text { Transwell migration, } \\
\text { Invasion, Xenograft } \\
\text { and liver met }\end{array}$ & Not performed & - & [174] \\
\hline
\end{tabular}


Table 7. Cont.

\begin{tabular}{|c|c|c|c|c|c|c|c|c|}
\hline Cell Line & Target & $\begin{array}{c}\text { EMT } \\
\text { Regulation }\end{array}$ & $\mathrm{KD} / \mathrm{KO} /$ Over-expression & Pathway/Mechanism & Functional Assay & $\begin{array}{c}\text { Prognostic } \\
\text { Association }\end{array}$ & $\begin{array}{c}\text { EMT } \\
\text { Activator }\end{array}$ & Reference \\
\hline PANC-1 & KLF8, Indirect & Positive, Direct & siRNA, Over-expression & $\begin{array}{l}\text { KLF8 IHC elevated in } \\
\text { PDAC, directly induces } \\
\text { FHL2 transcription via } \\
\text { promoter binding }\end{array}$ & WB, Invasion & Not performed & - & [175] \\
\hline GEMM & P73, Direct & Negative, Direct & GEMM & $\begin{array}{l}\text { P73 deficiency led to } \\
\text { stromal deposition and } \\
\text { EMT in PDAC tumours, } \\
\text { decreased BGN secretion, } \\
\text { required for tumour } \\
\text { suppressive functions of } \\
\text { TGF } \beta\end{array}$ & $\begin{array}{l}\text { GEMM, Transwell } \\
\text { assays }\end{array}$ & Not performed & - & [176] \\
\hline GEMM & PRRX1 & Positive, Direct & Overexpression & $\begin{array}{l}\text { PRRX1 a/b have discrete } \\
\text { functions in MET/EMT, } \\
\text { knockdown suppresses } \\
\text { tumour growth and EMT }\end{array}$ & $\begin{array}{l}\text { GEMM tumour } \\
\text { model, Xenograft }\end{array}$ & Not performed & - & [177] \\
\hline Capan-2 & TRIM28 & $\begin{array}{l}\text { Positive, } \\
\text { Indirect }\end{array}$ & Overexpression & $\begin{array}{l}\text { TRIM28 Overexpression } \\
\text { drove EMT and } \\
\text { Invasion, correlated } \\
\text { with T stage }\end{array}$ & $\begin{array}{c}\text { Transwell assays, } \\
\text { WB, Xenograft, IHC } \\
\text { of } 91 \text { PDAC }\end{array}$ & $\begin{array}{l}\text { Lymph node } \\
\text { metastasis and } \\
\text { survival }\end{array}$ & - & [178] \\
\hline PANC-1 & ETS1 & Positive, Direct & shRNA & $\begin{array}{c}\text { ETS1 knockdown } \\
\text { epithelialized PANC-1 } \\
\text { cells }\end{array}$ & $\begin{array}{l}\text { Scratch wound, } \\
\text { adhesion, qPCR for } \\
\text { EMT markers }\end{array}$ & Not performed & - & [179] \\
\hline $\begin{array}{l}\text { HDPE, } \\
\text { COLO-357 }\end{array}$ & NFE2L2 & Positive, Direct & siRNA/Over-expression & $\begin{array}{c}\text { NFE2L2 activation } \\
\text { enhanced TGF } \beta \text { induced } \\
\text { EMT in both } \\
\text { premalignant and } \\
\text { malignant cells }\end{array}$ & $\begin{array}{c}\text { Scratch wound, } \\
\text { Transwell assays, WB, } \\
\text { qPCR }\end{array}$ & Not performed & TGF $\beta$ & [180] \\
\hline $\begin{array}{l}\text { PANC-1, } \\
\text { HPAF-II }\end{array}$ & PDX1 & $\begin{array}{l}\text { Positive, } \\
\text { Indirect }\end{array}$ & shRNA, GEMM & $\begin{array}{l}\text { PDX1 has dual roles in } \\
\text { premalignant and } \\
\text { transformed cells. PDX1 } \\
\text { expression is reduced in } \\
\text { tumours and EMT }\end{array}$ & $\begin{array}{l}\text { Colony formation, } \\
\text { GEMMs, IHC of } 183 \\
\text { PDAC }\end{array}$ & $\begin{array}{l}\text { Inversely } \\
\text { prognostic for } \\
\text { survival }\end{array}$ & $\begin{array}{c}\text { TGF } \beta \\
\text { (PANC-1), } \\
\text { HGF } \\
\text { (HPAF-II) }\end{array}$ & [181] \\
\hline
\end{tabular}


Table 7. Cont.

\begin{tabular}{|c|c|c|c|c|c|c|c|c|}
\hline Cell Line & Target & $\begin{array}{c}\text { EMT } \\
\text { Regulation }\end{array}$ & KD/KO/Over-expression & Pathway/Mechanism & Functional Assay & $\begin{array}{l}\text { Prognostic } \\
\text { Association }\end{array}$ & $\begin{array}{c}\text { EMT } \\
\text { Activator }\end{array}$ & Reference \\
\hline PANC-1 & BCL9L & Positive, Direct & siRNA/Over-expression & $\begin{array}{l}\text { BCL9L knockdown } \\
\text { prevented EMT and } \\
\text { inhibited in vivo growth }\end{array}$ & $\begin{array}{l}\text { Proliferation, } \\
\text { Transwell assays, } \\
\text { Xenograft }\end{array}$ & Not performed & TGF $\beta$ & [182] \\
\hline GEMM & ETV1 & Positive, Direct & Overexpression & $\begin{array}{l}\text { ETV1 induces SPARC, } \\
\text { required for tumour } \\
\text { growth and metastasis } \\
\text { in vivo, EMT in vitro }\end{array}$ & Xenograft, Invasion & Not performed & - & [183] \\
\hline $\begin{array}{l}\text { ASPC-1, } \\
\text { SW1990 }\end{array}$ & EPAS1 & Positive, Direct & siRNA & $\begin{array}{c}\text { EPAS1 (HIF2 } \alpha) \text { IHC } \\
\text { expression high in } \\
\text { PDAC, and knockdown } \\
\text { inhibited EMT }\end{array}$ & $\begin{array}{c}\text { CHIP, Transwell } \\
\text { assays, IHC of } 70 \\
\text { PDAC }\end{array}$ & $\begin{array}{c}\text { Lymph node } \\
\text { metastasis, } \\
\text { differentiation }\end{array}$ & - & [184] \\
\hline $\begin{array}{c}\text { PANC-1 } \\
\text { BxPC-3 }\end{array}$ & SIX1 & $\begin{array}{l}\text { Positive, } \\
\text { Indirect }\end{array}$ & siRNA/shRNA & $\begin{array}{c}\text { SIX1 IHC expression } \\
\text { elevated in PDAC, } \\
\text { knockdown reduced } \\
\text { migration and tumour } \\
\text { size }\end{array}$ & $\begin{array}{c}\text { Migration, EMT } \\
\text { markers, PANC-1 } \\
\text { Xenograft, } \\
\text { CD44-/CD24+, IHC of } \\
\text { 139 PDAC }\end{array}$ & No & - & [185] \\
\hline Cfpac-1 & GRHL2 & Negative, Direct & siRNA & $\begin{array}{l}\text { GRHL2 IHC expression } \\
\text { elevated in normal duct } \\
\text { and liver metastases, } \\
\text { drives epithelial } \\
\text { phenotype. }\end{array}$ & $\begin{array}{l}\text { Proliferation, EMT } \\
\text { markers, Colony and } \\
\text { sphere formation, } \\
\text { drug resistance, IHC } \\
\text { of } 155 \text { PDAC }\end{array}$ & No & - & [186] \\
\hline PaTu8988S & GATA6 & Negative, Direct & shRNA/Over-expression & $\begin{array}{c}\text { GATA6 IHC expression } \\
\text { low in PDAC, Silencing } \\
\text { induced EMT }\end{array}$ & $\begin{array}{l}\text { chemo-resistance, IF, } \\
\text { Invasion, Xenograft, } \\
\text { IHC of } 58 \text { PDAC }\end{array}$ & $\begin{array}{l}\text { Inversely } \\
\text { prognostic for } \\
\text { survival }\end{array}$ & - & [187] \\
\hline
\end{tabular}


Table 8. Post transcriptional effectors. This table describes factors that may post transcriptionally modulate EMP by controlling stability of mRNA and hence expression of effector proteins. Candidates that exhibit clinical correlation with lymph node metastasis are shown in bold.

\begin{tabular}{|c|c|c|c|c|c|c|c|c|}
\hline Cell Line & Target & $\begin{array}{c}\text { EMT } \\
\text { Regulation }\end{array}$ & KD/KO/Over-expression & Pathway/Mechanism & Functional Assay & $\begin{array}{l}\text { Prognostic } \\
\text { Association }\end{array}$ & $\begin{array}{c}\text { EMT } \\
\text { Activator }\end{array}$ & Reference \\
\hline $\begin{array}{l}\text { Miapaca-2, } \\
\text { PANC-1, } \\
\text { Patu-8988 }\end{array}$ & HNRNPA2B1 & Positive, Direct & shRNA/Over-expression & $\begin{array}{l}\text { Knockdown epithelialized } \\
\text { cells, Over-expression } \\
\text { drove EMT through } \\
\text { ERK/SNAI1 pathway }\end{array}$ & $\begin{array}{l}\text { Cell viability, } \\
\text { Transwell assays, } \\
\text { PANC-1 Xenograft, } \\
\text { EMT markers }\end{array}$ & Not performed & - & [188] \\
\hline $\begin{array}{l}\text { SW1990, } \\
\text { BxPC-3 }\end{array}$ & YTHDF2 & Negative, Direct & shRNA & $\begin{array}{c}\text { Knockdown reduced } \\
\text { p-AKT, p-GSK-3b, } \\
\text { promoted EMT, YAP } \\
\text { knockdown reversed effect }\end{array}$ & $\begin{array}{c}\text { Proliferation, Colony } \\
\text { formation, Invasion, } \\
\text { adhesion }\end{array}$ & Not performed & - & [189] \\
\hline $\begin{array}{l}\text { Panc-1, } \\
\text { Patu8988 }\end{array}$ & Lnc TUG1 & Positive, Direct & shRNA & $\begin{array}{l}\text { Lnc TUG1 sponges } \\
\text { miR-382, preventing } \\
\text { repression of ezh2 }\end{array}$ & $\begin{array}{l}\text { Colony formation, } \\
\text { Transwell assays, WB }\end{array}$ & Not performed & - & [190] \\
\hline $\begin{array}{l}\text { Gemcitabine } \\
\text { resistant } \\
\text { BxPC-3 }\end{array}$ & DYNC2H1-4 & Positive, Direct & siRNA & $\begin{array}{l}\text { Lnc DYNC2H1-4 sponges } \\
\text { miR-145, upregulating } \\
\text { ZEB1, MMP3 and other } \\
\text { CSC markers }\end{array}$ & $\begin{array}{l}\text { Transwell assays, CSC } \\
\text { markers, Xenograft }\end{array}$ & Not performed & - & [191] \\
\hline $\begin{array}{l}\text { ASPC-1, } \\
\text { BxPC-3, } \\
\text { PANC-1 }\end{array}$ & miR-23 & Positive, Direct & miRNAs & $\begin{array}{c}\text { miR }-23 \text { promotes EMT by } \\
\text { regulating ESRP1, miR-23 } \\
\text { required for TGF } \beta \text { induced } \\
\text { EMT }\end{array}$ & $\begin{array}{c}\text { WB, Transwell assays, } \\
\text { Xenograft, qPCR of } 52 \\
\text { paired PDAC tumour } \\
\text { v normal }\end{array}$ & $\begin{array}{l}\text { Survival by } \\
\text { RNA }\end{array}$ & TGF $\beta$ & [192] \\
\hline $\begin{array}{l}\text { SW1990, } \\
\text { PANC-1, } \\
\text { BxPC-3, } \\
\text { CAPAN-1 }\end{array}$ & NORAD & Positive, Direct & shRNA/Over-expression & $\begin{array}{c}\text { Lnc NORAD acts as ceRNA } \\
\text { of miR-125a-3p, enhancing } \\
\text { RHOa and EMT }\end{array}$ & $\begin{array}{l}\text { Scratch wound, } \\
\text { Transwell assays, } \\
\text { Xenograft }\end{array}$ & Not performed & Hypoxia & [193] \\
\hline Panc-1 & Lnc H19 & Positive, Direct & siRNA & $\begin{array}{l}\text { H19 antagonised LET-7, } \\
\text { inducing HMGA-2 } \\
\text { mediated EMT }\end{array}$ & $\begin{array}{l}\text { Transwell assays, } \\
\text { scratch wound, WB }\end{array}$ & Not performed & - & [194] \\
\hline $\begin{array}{l}\text { ASPC-1, } \\
\text { BxPC-3 }\end{array}$ & LncRNA-ROR & Positive, Direct & shRNA/Over-expression & $\begin{array}{l}\text { LncRNA-ROR expression } \\
\text { induces ZEB1 and EMT }\end{array}$ & $\begin{array}{l}\text { Scratch wound, } \\
\text { Transwell assays, } \\
\text { Xenograft }\end{array}$ & Not performed & - & [195] \\
\hline
\end{tabular}


Table 8. Cont

\begin{tabular}{|c|c|c|c|c|c|c|c|c|}
\hline Cell Line & Target & $\begin{array}{c}\text { EMT } \\
\text { Regulation }\end{array}$ & KD/KO/Over-expression & Pathway/Mechanism & Functional Assay & $\begin{array}{c}\text { Prognostic } \\
\text { Association }\end{array}$ & $\begin{array}{c}\text { EMT } \\
\text { Activator }\end{array}$ & Reference \\
\hline $\begin{array}{l}\text { PANC-1, } \\
\text { BxPC-3, } \\
\text { COLO357 }\end{array}$ & $\begin{array}{l}\text { miR-100, miR } \\
-125 b\end{array}$ & $\begin{array}{l}\text { Positive, } \\
\text { Indirect }\end{array}$ & siRNA/CRISPR/Over-expression & $\begin{array}{c}\text { TGF } \beta \text { induced } \\
\text { lnc-miR100HG, which } \\
\text { codes for tumourigenic } \\
\text { miR 100, miR125b and } \\
\text { LET-7a. LIN28B also } \\
\text { induced by TGF } \beta \text {, } \\
\text { suppresses LET-7a activity }\end{array}$ & $\begin{array}{c}\text { miR Over-expression, } \\
\text { Xenograft, Scratch } \\
\text { wound, sphere } \\
\text { formation, RNAseq, } \\
\text { RIPseq }\end{array}$ & $\begin{array}{l}\text { Survival by } \\
\text { RNA }\end{array}$ & TGF $\beta$ & [109] \\
\hline $\begin{array}{l}\text { BxPC-3, } \\
\text { PANC-1, } \\
\text { CFPAC-1, } \\
\text { SW1990 }\end{array}$ & miR-361-3p & Positive, Direct & Over-expression & $\begin{array}{l}\text { miR-361-3p downregulates } \\
\text { DUSP2, preventing } \\
\text { inactivation of ERK1/2 }\end{array}$ & $\begin{array}{l}\text { Orthotopic metastasis, } \\
\text { Transwell assays }\end{array}$ & $\begin{array}{l}\text { Survival by } \\
\text { RNA }\end{array}$ & - & [196] \\
\hline Sw1990 & miR-1271 & Negative, Direct & miR Mimics, Inhibitors & $\begin{array}{l}\text { miR - } 1271 \text { inhibited EMT } \\
\text { and migration }\end{array}$ & $\begin{array}{c}\text { Proliferation, } \\
\text { Transwell migration } \\
\text { invasion, xenograft }\end{array}$ & Not performed & - & [197] \\
\hline Panc-1 & LSM1 & $\begin{array}{l}\text { Positive, } \\
\text { Indirect }\end{array}$ & Over-expression & $\begin{array}{l}\text { Lsm1 }(\mathrm{CaSm}) \text { induction } \\
\text { induced EMT and } \\
\text { proliferation, effecting } \\
\text { apoptotic and metastasis } \\
\text { gene expression }\end{array}$ & $\begin{array}{c}\text { Proliferation, anoikis, } \\
\text { Transwell assays, } \\
\text { chemo-resistance, } \\
\text { xenograft }\end{array}$ & Not performed & - & [198] \\
\hline KPCY & MTDH & $\begin{array}{l}\text { Positive, } \\
\text { Indirect }\end{array}$ & siRNA & $\begin{array}{c}\text { MTDH expression } \\
\text { promoted CSC and } \\
\text { metastasis, high } \\
\text { cytoplasmic expression by } \\
\text { IHC }\end{array}$ & $\begin{array}{c}\text { Spheroid formation, } \\
\text { orthotopic and } \\
\text { metastatic xenograft } \\
\text { models, IHC of } 134 \\
\text { PDAC }\end{array}$ & Survival & - & [199] \\
\hline $\begin{array}{l}\text { ASPC-1, } \\
\text { HS766t, } \\
\text { BxPC-3 }\end{array}$ & LIN28B & Positive, Direct & shRNA & $\begin{array}{c}\text { LIN28B IHC expression } \\
\text { high in PDAC, } \\
\text { suppression inhibited } \\
\text { proliferation and EMT }\end{array}$ & $\begin{array}{c}\text { Colony formation, } \\
\text { Proliferation, } \\
\text { migration, IHC of } \\
185 \text { PDAC tumours }\end{array}$ & $\begin{array}{l}\text { Survival, stage, } \\
\text { metastasis }\end{array}$ & - & [110] \\
\hline
\end{tabular}




\section{Conclusions}

Overall, investigation of the fundamental biology of EMP aims to combat local and metastatic invasion by providing a better understanding of the processes that allow cancer cells to dissociate from their epithelial adhesions to spread. EMP is a prominent driver of PDAC progression, thus highlighting the importance of our understanding of the subtleties of its regulation. The ability of EMP programs to direct cancer cells towards a drug resistant and migratory lineage capable of seeding local and distant recurrence presents a significant barrier to current treatment regimens. Therefore, the identification of new candidate molecules regulating these processes are crucial to inform targeted therapies and provide insights into the vulnerabilities of heterogeneous populations of tumour cells present in PDAC.

It is clear from this ever-growing list of EMP effectors in PDAC cells alone, that much work remains to delineate their collective interactions within and beyond our current understanding on EMP signaling pathways. While candidates have been shown to play roles in aspects of EMP signaling and associated phenotypes, significant support is required for their mechanisms of action to make concrete conclusions about their directive actions in cancer. Our understanding of receptor mediated canonical signaling through PI3K/AKT, MAPK, NFKB and other well studied cell cycle pathways has required decades to tease apart, and the subtleties of EMP programs provides a similar challenge. Open source integrative tools such as Reactome [200], WikiPathways [201], String [202], and Cytoscape [203] provide platforms for researchers to combine such analyses to build upon our current understanding and fill knowledge gaps in the field of cancer biology. In this way, progress may be made to better understand and discover properties that may be modulated in concert to control EMP in cancer.

In vitro and xenograft tumour modelling and manipulation of target molecules often demonstrates a role in cancer cell migration and tumour formation, however stronger evidence for their physiological role in regulating EMP, metastasis and therapy resistance may require GEMMs. The use of in vivo manipulation of PDAC GEMM models using targeted CRISPR approaches may be such a route towards a system that better recapitulates the spontaneity and heterogeneity of human tumours [204].

Conflicts of Interest: The authors declare no conflict of interest.

\section{References}

1. Siegel, R.L.; Miller, K.D.; Jemal, A. Cancer statistics, 2019. CA Cancer J. Clin. 2019, 69, 7-34. [CrossRef] [PubMed]

2. Rahib, L.; Smith, B.D.; Aizenberg, R.; Rosenzweig, A.B.; Fleshman, J.M.; Matrisian, L.M. Projecting cancer incidence and deaths to 2030: The unexpected burden of thyroid, liver, and pancreas cancers in the united states. Cancer Res. 2014, 74, 2913-2921. [CrossRef] [PubMed]

3. Vogelstein, B.; Papadopoulos, N.; Velculescu, V.E.; Zhou, S.; Diaz, L.A., Jr.; Kinzler, K.W. Cancer genome landscapes. Science 2013, 339, 1546-1558. [CrossRef] [PubMed]

4. Weinstein, J.N.; Collisson, E.A.; Mills, G.B.; Shaw, K.R.; Ozenberger, B.A.; Ellrott, K.; Shmulevich, I.; Sander, C.; Stuart, J.M. The cancer genome atlas pan-cancer analysis project. Nat. Genet. 2013, 45, 1113-1120. [CrossRef]

5. Waddell, N.; Pajic, M.; Patch, A.M.; Chang, D.K.; Kassahn, K.S.; Bailey, P.; Johns, A.L.; Miller, D.; Nones, K.; Quek, K.; et al. Whole genomes redefine the mutational landscape of pancreatic cancer. Nature 2015, 518, 495-501. [CrossRef]

6. Bailey, P.; Chang, D.K.; Nones, K.; Johns, A.L.; Patch, A.-M.; Gingras, M.-C.; Miller, D.K.; Christ, A.N.; Bruxner, T.J.C.; Quinn, M.C.; et al. Genomic analyses identify molecular subtypes of pancreatic cancer. Nature 2016, 531, 47-52. [CrossRef]

7. Maitra, A.; Hruban, R.H. Pancreatic cancer. Annu. Rev. Pathol. 2008, 3, 157-188. [CrossRef]

8. Jones, S.; Zhang, X.; Parsons, D.W.; Lin, J.C.; Leary, R.J.; Angenendt, P.; Mankoo, P.; Carter, H.; Kamiyama, H.; Jimeno, A.; et al. Core signaling pathways in human pancreatic cancers revealed by global genomic analyses. Science 2008, 321, 1801-1806. [CrossRef] 
9. Benjamin, J.; Hruban, H.R.R.; Aguirre, A.J.; Moffitt, R.A.; Yeh, J.J.; Chip, S.A.; Robertson, G.; Cherniack, A.D.; Gupta, M.; Getz, G.; et al. Integrated genomic characterization of pancreatic ductal adenocarcinoma. Cancer Cell 2017, 32, 185-203.e113. [CrossRef]

10. Hruban, R.H.; Maitra, A.; Schulick, R.; Laheru, D.; Herman, J.; Kern, S.E.; Goggins, M. Emerging molecular biology of pancreatic cancer. Gastrointest. Cancer Res. GCR 2008, 2, S10-S15.

11. Collisson, E.A.; Sadanandam, A.; Olson, P.; Gibb, W.J.; Truitt, M.; Gu, S.; Cooc, J.; Weinkle, J.; Kim, G.E.; Jakkula, L.; et al. Subtypes of pancreatic ductal adenocarcinoma and their differing responses to therapy. Nat. Med. 2011, 17, 500-503. [CrossRef] [PubMed]

12. Maurer, C.; Holmstrom, S.R.; He, J.; Laise, P.; Su, T.; Ahmed, A.; Hibshoosh, H.; Chabot, J.A.; Oberstein, P.E.; Sepulveda, A.R.; et al. Experimental microdissection enables functional harmonisation of pancreatic cancer subtypes. Gut 2019, 68, 1034-1043. [CrossRef] [PubMed]

13. Zhao, L.; Zhao, H.; Yan, H. Gene expression profiling of 1200 pancreatic ductal adenocarcinoma reveals novel subtypes. BMC Cancer 2018, 18, 603. [CrossRef] [PubMed]

14. Ligorio, M.; Sil, S.; Malagon-Lopez, J.; Nieman, L.T.; Misale, S.; Di Pilato, M.; Ebright, R.Y.; Karabacak, M.N.; Kulkarni, A.S.; Liu, A.; et al. Stromal microenvironment shapes the intratumoral architecture of pancreatic cancer. Cell 2019, 178, 160-175.e27. [CrossRef] [PubMed]

15. Peng, J.; Sun, B.-F.; Chen, C.-Y.; Zhou, J.-Y.; Chen, Y.-S.; Chen, H.; Liu, L.; Huang, D.; Jiang, J.; Cui, G.-S.; et al. Single-cell RNA-seq highlights intra-tumoral heterogeneity and malignant progression in pancreatic ductal adenocarcinoma. Cell Res. 2019, 29, 725-738. [CrossRef]

16. Moffitt, R.A.; Marayati, R.; Flate, E.L.; Volmar, K.E.; Loeza, S.G.H.; Hoadley, K.A.; Rashid, N.U.; Williams, L.A.; Eaton, S.C.; Chung, A.H.; et al. Virtual microdissection identifies distinct tumor- and stroma-specific subtypes of pancreatic ductal adenocarcinoma. Nat. Genet. 2015, 47, 1168-1178. [CrossRef]

17. Spivak-Kroizman, T.R.; Hostetter, G.; Posner, R.; Aziz, M.; Hu, C.; Demeure, M.J.; Von Hoff, D.; Hingorani, S.R.; Palculict, T.B.; Izzo, J.; et al. Hypoxia triggers hedgehog-mediated tumor-stromal interactions in pancreatic cancer. Cancer Res. 2013, 73, 3235-3247. [CrossRef]

18. Moir, J.A.; Mann, J.; White, S.A. The role of pancreatic stellate cells in pancreatic cancer. Surg. Oncol. 2015, 24, 232-238. [CrossRef]

19. Feig, C.; Gopinathan, A.; Neesse, A.; Chan, D.S.; Cook, N.; Tuveson, D.A. The Pancreas Cancer Microenvironment; AACR: Philadelphia, PA, USA, 2012.

20. Neesse, A.; Michl, P.; Frese, K.K.; Feig, C.; Cook, N.; Jacobetz, M.A.; Lolkema, M.P.; Buchholz, M.; Olive, K.P.; Gress, T.M. Stromal biology and therapy in pancreatic cancer. Gut 2011, 60, 861-868. [CrossRef]

21. Korc, M. Pancreatic cancer-associated stroma production. Am. J. Surg. 2007, 194, S84-S86. [CrossRef]

22. Hanahan, D.; Weinberg, R.A. Hallmarks of cancer: The next generation. Cell 2011, 144, 646-674. [CrossRef] [PubMed]

23. Xu, Z.; Pothula, S.P.; Wilson, J.S.; Apte, M.V. Pancreatic cancer and its stroma: A conspiracy theory. World J. Gastroenterol. WJG 2014, 20, 11216-11229. [CrossRef] [PubMed]

24. Mahadevan, D.; Von Hoff, D.D. Tumor-stroma interactions in pancreatic ductal adenocarcinoma. Mol. Cancer Therap. 2007, 6, 1186-1197. [CrossRef] [PubMed]

25. Thomas, D.; Radhakrishnan, P. Tumor-stromal crosstalk in pancreatic cancer and tissue fibrosis. Mol. Cancer 2019, 18, 14. [CrossRef] [PubMed]

26. Trelstad, R.L.; Hay, E.D.; Revel, J.D. Cell contact during early morphogenesis in the chick embryo. Dev. Biol. 1967, 16, 78-106. [CrossRef]

27. Huber, M.A.; Kraut, N.; Beug, H. Molecular requirements for epithelial-mesenchymal transition during tumor progression. Curr. Opin. Cell Biol. 2005, 17, 548-558. [CrossRef]

28. Tsai, J.H.; Yang, J. Epithelial-mesenchymal plasticity in carcinoma metastasis. Genes Dev. 2013, 27, $2192-2206$. [CrossRef]

29. Giovannetti, E.; van der Borden, C.L.; Frampton, A.E.; Ali, A.; Firuzi, O.; Peters, G.J. Never let it go: Stopping key mechanisms underlying metastasis to fight pancreatic cancer. Semin. Cancer Biol. 2017, 44, 43-59. [CrossRef]

30. Du, Y.X.; Liu, Z.W.; You, L.; Wu, W.M.; Zhao, Y.P. Advances in understanding the molecular mechanism of pancreatic cancer metastasis. Hepatobiliary Pancreat. Dis. Int. 2016, 15, 361-370. [CrossRef] 
31. Beuran, M.; Negoi, I.; Paun, S.; Ion, A.D.; Bleotu, C.; Negoi, R.I.; Hostiuc, S. The epithelial to mesenchymal transition in pancreatic cancer: A systematic review. Pancreatol. Off. J. Int. Assoc. Pancreatol. 2015, 15, 217-225. [CrossRef]

32. Satoh, K.; Hamada, S.; Shimosegawa, T. Involvement of epithelial to mesenchymal transition in the development of pancreatic ductal adenocarcinoma. J. Gastroenterol. 2015, 50, 140-146. [CrossRef] [PubMed]

33. Hamada, S.; Satoh, K.; Masamune, A.; Shimosegawa, T. Regulators of epithelial mesenchymal transition in pancreatic cancer. Front. Physiol. 2012, 3, 254. [CrossRef] [PubMed]

34. Bailey, J.M.; Leach, S.D. Signaling pathways mediating epithelial-mesenchymal crosstalk in pancreatic cancer: Hedgehog, Notch and TGFBeta. In Pancreatic Cancer and Tumor Microenvironment; Grippo, P.J., Munshi, H.G., Eds.; Transworld Research Network: Trivandrum, India, 2012.

35. Dangi-Garimella, S.; Krantz, S.B.; Shields, M.A.; Grippo, P.J.; Munshi, H.G. Epithelial-mesenchymal transition and pancreatic cancer progression. In Pancreatic Cancer and Tumor Microenvironment; Grippo, P.J., Munshi, H.G., Eds.; Transworld Research Network: Trivandrum, India, 2012.

36. Chaffer, C.L.; San Juan, B.P.; Lim, E.; Weinberg, R.A. EMT, cell plasticity and metastasis. Cancer Metastasis Rev. 2016, 35, 645-654. [CrossRef] [PubMed]

37. Trager, M.M.; Dhayat, S.A. Epigenetics of epithelial-to-mesenchymal transition in pancreatic carcinoma. Int. J. Cancer 2017, 141, 24-32. [CrossRef] [PubMed]

38. Elaskalani, O.; Razak, N.B.; Falasca, M.; Metharom, P. Epithelial-mesenchymal transition as a therapeutic target for overcoming chemoresistance in pancreatic cancer. World J. Gastrointest. Oncol. 2017, 9, 37-41. [CrossRef] [PubMed]

39. Gaianigo, N.; Melisi, D.; Carbone, C. EMT and treatment resistance in pancreatic cancer. Cancers 2017, 9, 122. [CrossRef]

40. Ishiwata, T. Cancer stem cells and epithelial-mesenchymal transition: Novel therapeutic targets for cancer. Pathol. Int. 2016, 66, 601-608. [CrossRef] [PubMed]

41. Kyuno, D.; Yamaguchi, H.; Ito, T.; Kono, T.; Kimura, Y.; Imamura, M.; Konno, T.; Hirata, K.; Sawada, N.; Kojima, T. Targeting tight junctions during epithelial to mesenchymal transition in human pancreatic cancer. World J. Gastroenterol. WJG 2014, 20, 10813-10824. [CrossRef]

42. Shibue, T. EMT, CSCs, and drug resistance: The mechanistic link and clinical implications. Nat. Rev. Clin. Oncol. 2017, 14, 611-629. [CrossRef]

43. Hawa, Z.; Haque, I.; Ghosh, A.; Banerjee, S.; Harris, L.; Banerjee, S.K. The miRacle in pancreatic cancer by miRNAs: Tiny angels or devils in disease progression. Int. J. Mol. Sci. 2016, 17, 809. [CrossRef]

44. Brabletz, S.; Brabletz, T. The ZEB/miR-200 feedback loop-A motor of cellular plasticity in development and cancer? EMBO Rep. 2010, 11, 670-677. [CrossRef] [PubMed]

45. Rhim, A.D. Epithelial to mesenchymal transition and the generation of stem-like cells in pancreatic cancer. Pancreatology 2013, 13, 114-117. [CrossRef] [PubMed]

46. Zhan, H.X.; Xu, J.W.; Wu, D.; Zhang, T.P.; Hu, S.Y. Pancreatic cancer stem cells: New insight into a stubborn disease. Cancer Lett. 2015, 357, 429-437. [CrossRef] [PubMed]

47. Vaz, A.P.; Ponnusamy, M.P.; Seshacharyulu, P.; Batra, S.K. A concise review on the current understanding of pancreatic cancer stem cells. J. Cancer Stem Cell Res. 2014, 2, e1004. [CrossRef] [PubMed]

48. Castellanos, J.A.; Merchant, N.B.; Nagathihalli, N.S. Emerging targets in pancreatic cancer: Epithelialmesenchymal transition and cancer stem cells. Onco Targets Ther. 2013, 6, 1261-1267. [CrossRef] [PubMed]

49. Karamitopoulou, E. Tumor budding cells, cancer stem cells and epithelial-mesenchymal transition-type cells in pancreatic cancer. Front. Oncol. 2012, 2, 209. [CrossRef]

50. Chuai, G.; Yang, F.; Yan, J.; Chen, Y.; Ma, Q.; Zhou, C.; Zhu, C.; Gu, F.; Liu, Q. Deciphering relationship between microhomology and in-frame mutation occurrence in human CRISPR-based gene knockout. Mol. Ther. Nucleic Acids 2016, 5, e323. [CrossRef]

51. Nguyen, D.X.; Bos, P.D.; Massague, J. Metastasis: from dissemination to organ-specific colonization. Nat Rev Cancer 2009, 9, 274-284. [CrossRef]

52. Nieto, J.; Grossbard, M.L.; Kozuch, P. Metastatic pancreatic cancer 2008: Is the glass less empty? Oncologist 2008, 13, 562-576. [CrossRef] 
53. Schmalhofer, O.; Brabletz, S.; Brabletz, T. E-cadherin, beta-catenin, and ZEB1 in malignant progression of cancer. Cancer Metastasis Rev. 2009, 28, 151-166. [CrossRef]

54. Nakajima, S.; Doi, R.; Toyoda, E.; Tsuji, S.; Wada, M.; Koizumi, M.; Tulachan, S.S.; Ito, D.; Kami, K.; Mori, T.; et al. N-cadherin expression and epithelial-mesenchymal transition in pancreatic carcinoma. Clin. Cancer Res. Off. J. Am. Assoc. Cancer Res. 2004, 10, 4125-4133. [CrossRef] [PubMed]

55. Peinado, H.; Portillo, F.; Cano, A. Transcriptional regulation of cadherins during development and carcinogenesis. Int. J. Dev. Biol. 2004, 48, 365-375. [CrossRef] [PubMed]

56. Hotz, B.; Arndt, M.; Dullat, S.; Bhargava, S.; Buhr, H.J.; Hotz, H.G. Epithelial to mesenchymal transition: Expression of the regulators snail, slug, and twist in pancreatic cancer. Clin. Cancer Res. Off. J. Am. Assoc. Cancer Res. 2007, 13, 4769-4776. [CrossRef] [PubMed]

57. Brabletz, T.; Jung, A.; Reu, S.; Porzner, M.; Hlubek, F.; Kunz-Schughart, L.A.; Knuechel, R.; Kirchner, T. Variable beta-catenin expression in colorectal cancers indicates tumor progression driven by the tumor environment. Proc. Natl. Acad. Sci. USA 2001, 98, 10356-10361. [CrossRef]

58. Joo, Y.E.; Rew, J.S.; Park, C.S.; Kim, S.J. Expression of E-cadherin, alpha- and beta-catenins in patients with pancreatic adenocarcinoma. Pancreatol. Off. J. Int. Assoc. Pancreatol. 2002, 2, 129-137. [CrossRef]

59. Yin, T.; Wang, C.; Liu, T.; Zhao, G.; Zha, Y.; Yang, M. Expression of snail in pancreatic cancer promotes metastasis and chemoresistance. J. Surg. Res. 2007, 141, 196-203. [CrossRef]

60. Oida, Y.; Yamazaki, H.; Tobita, K.; Mukai, M.; Ohtani, Y.; Miyazaki, N.; Abe, Y.; Imaizumi, T.; Makuuchi, H.; Ueyama, Y.; et al. Increased S100A4 expression combined with decreased E-cadherin expression predicts a poor outcome of patients with pancreatic cancer. Oncol. Rep. 2006, 16, 457-463. [CrossRef]

61. Javle, M.M.; Gibbs, J.F.; Iwata, K.K.; Pak, Y.; Rutledge, P.; Yu, J.; Black, J.D.; Tan, D.; Khoury, T. Epithelial-mesenchymal transition (EMT) and activated extracellular signal-regulated kinase (p-Erk) in surgically resected pancreatic cancer. Ann. Surg. Oncol. 2007, 14, 3527-3533. [CrossRef]

62. Yamada, S.; Fuchs, B.C.; Fujii, T.; Shimoyama, Y.; Sugimoto, H.; Nomoto, S.; Takeda, S.; Tanabe, K.K.; Kodera, Y.; Nakao, A. Epithelial-to-mesenchymal transition predicts prognosis of pancreatic cancer. Surgery 2013, 154, 946-954. [CrossRef]

63. Wang, J.; Nikhil, K.; Viccaro, K.; Chang, L.; Jacobsen, M.; Sandusky, G.; Shah, K. The Aurora-A-Twist1 axis promotes highly aggressive phenotypes in pancreatic carcinoma. J. Cell Sci. 2017, 130, 1078-1093. [CrossRef]

64. Wang, Z.; Zhao, L.; Xiao, Y.; Gao, Y.; Zhao, C. Snail transcript levels in diagnosis of pancreatic carcinoma with fine-needle aspirate. Br. J. Biomed. Sci. 2015, 72, 107-110. [CrossRef] [PubMed]

65. Yamazaki, K.; Masugi, Y.; Effendi, K.; Tsujikawa, H.; Hiraoka, N.; Kitago, M.; Shinoda, M.; Itano, O.; Tanabe, M.; Kitagawa, Y.; et al. Upregulated SMAD3 promotes epithelial-mesenchymal transition and predicts poor prognosis in pancreatic ductal adenocarcinoma. Lab. Investing. J. Tech. Methods Pathol. 2014, 94, 683-691. [CrossRef] [PubMed]

66. Masugi, Y.; Yamazaki, K.; Hibi, T.; Aiura, K.; Kitagawa, Y.; Sakamoto, M. Solitary cell infiltration is a novel indicator of poor prognosis and epithelial-mesenchymal transition in pancreatic cancer. Hum. Pathol. 2010, 41, 1061-1068. [CrossRef] [PubMed]

67. Galvan, J.A.; Zlobec, I.; Wartenberg, M.; Lugli, A.; Gloor, B.; Perren, A.; Karamitopoulou, E. Expression of E-cadherin repressors SNAIL, ZEB1 and ZEB2 by tumour and stromal cells influences tumour-budding phenotype and suggests heterogeneity of stromal cells in pancreatic cancer. Br. J. Cancer 2015, 112, 1944-1950. [CrossRef] [PubMed]

68. Tarin, D.; Thompson, E.W.; Newgreen, D.F. The fallacy of epithelial mesenchymal transition in neoplasia. Cancer Res. 2005, 65, 5996-6000. [CrossRef]

69. Ledford, H. Cancer theory faces doubts. Nature 2011, 472, 273. [CrossRef]

70. Rhim, A.D.; Mirek, E.T.; Aiello, N.M.; Maitra, A.; Bailey, J.M.; McAllister, F.; Reichert, M.; Beatty, G.L.; Rustgi, A.K.; Vonderheide, R.H.; et al. EMT and dissemination precede pancreatic tumor formation. Cell 2012, 148, 349-361. [CrossRef]

71. Zheng, X.; Carstens, J.L.; Kim, J.; Scheible, M.; Kaye, J.; Sugimoto, H.; Wu, C.C.; LeBleu, V.S.; Kalluri, R. Epithelial-to-mesenchymal transition is dispensable for metastasis but induces chemoresistance in pancreatic cancer. Nature 2015, 527, 525-530. [CrossRef] 
72. Aiello, N.M.; Brabletz, T.; Kang, Y.; Nieto, M.A.; Weinberg, R.A.; Stanger, B.Z. Upholding a role for EMT in pancreatic cancer metastasis. Nature 2017, 547, E7-E8. [CrossRef]

73. Krebs, A.M.; Mitschke, J.; Lasierra Losada, M.; Schmalhofer, O.; Boerries, M.; Busch, H.; Boettcher, M.; Mougiakakos, D.; Reichardt, W.; Bronsert, P.; et al. The EMT-activator Zeb1 is a key factor for cell plasticity and promotes metastasis in pancreatic cancer. Nat. Cell Biol. 2017, 19, 518-529. [CrossRef]

74. Chen, Y.; LeBleu, V.S.; Carstens, J.L.; Sugimoto, H.; Zheng, X.; Malasi, S.; Saur, D.; Kalluri, R. Dual reporter genetic mouse models of pancreatic cancer identify an epithelial-to-mesenchymal transition-independent metastasis program. EMBO Mol. Med. 2018, 10, e9085. [CrossRef] [PubMed]

75. Thompson, E.W.; Nagaraj, S.H. Transition states that allow cancer to spread. Nature 2018, 556, 442-444. [CrossRef] [PubMed]

76. Pastushenko, I.; Brisebarre, A.; Sifrim, A.; Fioramonti, M.; Revenco, T.; Boumahdi, S.; Van Keymeulen, A.; Brown, D.; Moers, V.; Lemaire, S.; et al. Identification of the tumour transition states occurring during EMT. Nature 2018, 556, 463-468. [CrossRef] [PubMed]

77. Pastushenko, I.; Blanpain, C. EMT Transition states during tumor progression and metastasis. Trends Cell Biol. 2019, 29, 212-226. [CrossRef] [PubMed]

78. Brabletz, S.; Brabletz, T.; Stemmler, M.P. Road to perdition: Zeb1-dependent and -independent ways to metastasis. Cell Cycle 2017, 16, 1729-1730. [CrossRef] [PubMed]

79. Lamouille, S.; Xu, J.; Derynck, R. Molecular mechanisms of epithelial-mesenchymal transition. Nat. Rev. Mol. Cell Biol. 2014, 15, 178-196. [CrossRef] [PubMed]

80. Gonzalez, D.M.; Medici, D. Signaling mechanisms of the epithelial-mesenchymal transition. Sci. Signal. 2014, 7, re8. [CrossRef]

81. David, C.J.; Huang, Y.-H.; Chen, M.; Su, J.; Zou, Y.; Bardeesy, N.; Iacobuzio-Donahue, C.A.; Massagué, J. TGF- $\beta$ Tumor Suppression through a Lethal EMT. Cell 2016, 164, 1015-1030. [CrossRef]

82. Glazer, E.S.; Welsh, E.; Pimiento, J.M.; Teer, J.K.; Malafa, M.P. TGF $\beta 1$ overexpression is associated with improved survival and low tumor cell proliferation in patients with early-stage pancreatic ductal adenocarcinoma. Oncotarget 2017, 8, 999. [CrossRef]

83. Rowland-Goldsmith, M.A.; Maruyama, H.; Kusama, T.; Ralli, S.; Korc, M. Soluble type II transforming growth factor-beta (TGF-beta) receptor inhibits TGF-beta signaling in COLO-357 pancreatic cancer cells in vitro and attenuates tumor formation. Clin. Cancer Res. Off. J. Am. Assoc. Cancer Res. 2001, 7, 2931-2940.

84. Wagner, M.; Kleeff, J.; Friess, H.; Buchler, M.W.; Korc, M. Enhanced expression of the type II transforming growth factor-beta receptor is associated with decreased survival in human pancreatic cancer. Pancreas 1999, 19, 370-376. [CrossRef] [PubMed]

85. Chuvin, N.; Vincent, D.F.; Pommier, R.M.; Alcaraz, L.B.; Gout, J.; Caligaris, C.; Yacoub, K.; Cardot, V.; Roger, E.; Kaniewski, B.; et al. Acinar-to-Ductal Metaplasia Induced by Transforming Growth Factor Beta Facilitates KRAS(G12D)-driven Pancreatic Tumorigenesis. Cell. Mol. Gastroenterol. Hepatol. 2017, 4, $263-282$. [CrossRef] [PubMed]

86. Subramanian, G.; Schwarz, R.E.; Higgins, L.; McEnroe, G.; Chakravarty, S.; Dugar, S.; Reiss, M. Targeting endogenous transforming growth factor beta receptor signaling in SMAD4-deficient human pancreatic carcinoma cells inhibits their invasive phenotype1. Cancer Res. 2004, 64, 5200-5211. [CrossRef] [PubMed]

87. Janda, E.; Lehmann, K.; Killisch, I.; Jechlinger, M.; Herzig, M.; Downward, J.; Beug, H.; Grunert, S. Ras and TGF[beta] cooperatively regulate epithelial cell plasticity and metastasis: Dissection of Ras signaling pathways. J. Cell Biol. 2002, 156, 299-313. [CrossRef] [PubMed]

88. Al-Ismaeel, Q.; Neal, C.P.; Al-Mahmoodi, H.; Almutairi, Z.; Al-Shamarti, I.; Straatman, K.; Jaunbocus, N.; Irvine, A.; Issa, E.; Moreman, C.; et al. ZEB1 and IL-6/11-STAT3 signaling cooperate to define invasive potential of pancreatic cancer cells via differential regulation of the expression of S100 proteins. Br. J. Cancer 2019, 121, 65-75. [CrossRef] [PubMed]

89. Ram Makena, M.; Gatla, H.; Verlekar, D.; Sukhavasi, S.; Pandey, M.K.; Pramanik, K.C. Wnt/beta-Catenin signaling: The culprit in pancreatic carcinogenesis and therapeutic resistance. Int. J. Mol. Sci. 2019, 20, 4242. [CrossRef]

90. Witte, D.; Otterbein, H.; Forster, M.; Giehl, K.; Zeiser, R.; Lehnert, H.; Ungefroren, H. Negative regulation of TGF-beta1-induced MKK6-p38 and MEK-ERK signaling and epithelial-mesenchymal transition by Rac1b. Sci. Rep. 2017, 7, 17313. [CrossRef] 
91. Wang, G.; Yu, Y.; Sun, C.; Liu, T.; Liang, T.; Zhan, L.; Lin, X.; Feng, X.H. STAT3 selectively interacts with Smad3 to antagonize TGF-beta signaling. Oncogene 2016, 35, 4388-4398. [CrossRef]

92. Sheng, W.; Chen, C.; Dong, M.; Wang, G.; Zhou, J.; Song, H.; Li, Y.; Zhang, J.; Ding, S. Calreticulin promotes EGF-induced EMT in pancreatic cancer cells via Integrin/EGFR-ERK/MAPK signaling pathway. Cell Death Dis. 2017, 8, e3147. [CrossRef]

93. Witte, D.; Bartscht, T.; Kaufmann, R.; Pries, R.; Settmacher, U.; Lehnert, H.; Ungefroren, H. TGF-beta1-induced cell migration in pancreatic carcinoma cells is RAC1 and NOX4-dependent and requires RAC1 and NOX4-dependent activation of p38 MAPK. Oncol. Rep. 2017, 38, 3693-3701. [CrossRef]

94. Kumar, K.; Chow, C.R.; Ebine, K.; Arslan, A.D.; Kwok, B.; Bentrem, D.J.; Eckerdt, F.D.; Platanias, L.C.; Munshi, H.G. Differential regulation of ZEB1 and EMT by MAPK-interacting protein Kinases (MNK) and eIF4E in pancreatic cancer. Mol. Cancer Res. MCR 2016, 14, 216-227. [CrossRef] [PubMed]

95. Yang, A.D.; Camp, E.R.; Fan, F.; Shen, L.; Gray, M.J.; Liu, W.; Somcio, R.; Bauer, T.W.; Wu, Y.; Hicklin, D.J.; et al. Vascular endothelial growth factor receptor-1 activation mediates epithelial to mesenchymal transition in human pancreatic carcinoma cells. Cancer Res. 2006, 66, 46-51. [CrossRef] [PubMed]

96. Wang, Y.; Jin, G.; Li, Q.; Wang, Z.; Hu, W.; Li, P.; Li, S.; Wu, H.; Kong, X.; Gao, J.; et al. Hedgehog Signaling non-canonical activated by pro-inflammatory cytokines in pancreatic ductal adenocarcinoma. J. Cancer 2016, 7, 2067-2076. [CrossRef] [PubMed]

97. Huang, H.; Svoboda, R.A.; Lazenby, A.J.; Saowapa, J.; Chaika, N.; Ding, K.; Wheelock, M.J.; Johnson, K.R. Up-regulation of $\mathrm{N}$-cadherin by collagen i-activated discoidin domain receptor 1 in pancreatic cancer requires the adaptor molecule Shc1. J. Biol. Chem. 2016, 291, 23208-23223. [CrossRef] [PubMed]

98. Zhu, H.; Qin, H.; Li, D.M.; Liu, J.; Zhao, Q. Effect of PPM1H on malignant phenotype of human pancreatic cancer cells. Oncol. Rep. 2016, 36, 2926-2934. [CrossRef]

99. Ellenrieder, V.; Hendler, S.F.; Boeck, W.; Activation, S.-R.K.; Seufferlein, T.; Menke, A.; Ruhland, C.; Adler, G.; Gress, T.M. Transforming growth factor $\beta 1$ treatment leads to an epithelial-mesenchymal transdifferentiation of pancreatic cancer cells requiring extracellular signal-regulated kinase 2 activation. Cancer Res. 2001, $61,4222-4228$.

100. Buonato, J.M.; Lan, I.S.; Lazzara, M.J. EGF augments TGFBeta-induced epithelial-mesenchymal transition by promoting SHP2 binding to GAB1. J. Cell Sci. 2015, 128, 3898-3909. [CrossRef]

101. Maier, H.J.; Schmidt-Strassburger, U.; Huber, M.A.; Wiedemann, E.M.; Beug, H.; Wirth, T. NF-kappaB promotes epithelial-mesenchymal transition, migration and invasion of pancreatic carcinoma cells. Cancer Lett. 2010, 295, 214-228. [CrossRef]

102. Oyanagi, J.; Kojima, N.; Sato, H.; Higashi, S.; Kikuchi, K.; Sakai, K.; Matsumoto, K.; Miyazaki, K. Inhibition of transforming growth factor-beta signaling potentiates tumor cell invasion into collagen matrix induced by fibroblast-derived hepatocyte growth factor. Exp. Cell Res. 2014, 326, 267-279. [CrossRef]

103. Wajant, H.; Pfizenmaier, K.; Scheurich, P. Tumor necrosis factor signaling. Cell Death Differ. 2003, 10, 45-65. [CrossRef]

104. Xu, J.; Lamouille, S.; Derynck, R. TGF- $\beta$-induced epithelial to mesenchymal transition. Cell Res. 2009, 19, 156-172. [CrossRef] [PubMed]

105. Liu, M.; Quek, L.E.; Sultani, G.; Turner, N. Epithelial-mesenchymal transition induction is associated with augmented glucose uptake and lactate production in pancreatic ductal adenocarcinoma. Cancer Metab. 2016, 4, 19. [CrossRef] [PubMed]

106. Gao, S.; Sun, Y.; Zhang, X.; Hu, L.; Liu, Y.; Chua, C.Y.; Phillips, L.M.; Ren, H.; Fleming, J.B.; Wang, H.; et al. IGFBP2 Activates the NF-kappaB Pathway to Drive Epithelial-Mesenchymal Transition and Invasive Character in Pancreatic Ductal Adenocarcinoma. Cancer Res 2016, 76, 6543-6554. [CrossRef] [PubMed]

107. Masugi, Y.; Yamazaki, K.; Emoto, K.; Effendi, K.; Tsujikawa, H.; Kitago, M.; Itano, O.; Kitagawa, Y.; Sakamoto, M. Upregulation of integrin beta4 promotes epithelial-mesenchymal transition and is a novel prognostic marker in pancreatic ductal adenocarcinoma. Lab. Investig. J. Tech. Methods Pathol. 2015, 95, 308-319. [CrossRef]

108. Chen, J.; Li, Q.; An, Y.; Lv, N.; Xue, X.; Wei, J.; Jiang, K.; Wu, J.; Gao, W.; Qian, Z.; et al. CEACAM6 induces epithelial-mesenchymal transition and mediates invasion and metastasis in pancreatic cancer. Int. J. Oncol. 2013, 43, 877-885. [CrossRef] 
109. Ottaviani, S.; Stebbing, J.; Frampton, A.E.; Zagorac, S.; Krell, J.; de Giorgio, A.; Trabulo, S.M.; Nguyen, V.T.M.; Magnani, L.; Feng, H.; et al. TGF- $\beta$ induces miR-100 and miR-125b but blocks let-7a through LIN28B controlling PDAC progression. Nat. Commun. 2018, 9. [CrossRef]

110. Wang, Y.; Li, J.; Guo, S.; Ouyang, Y.; Yin, L.; Liu, S.; Zhao, Z.; Yang, J.; Huang, W.; Qin, H.; et al. Lin28B facilitates the progression and metastasis of pancreatic ductal adenocarcinoma. Oncotarget 2017, 8, 60414-60428. [CrossRef]

111. Guo, Q.; Qin, W. DKK3 blocked translocation of beta-catenin/EMT induced by hypoxia and improved gemcitabine therapeutic effect in pancreatic cancer Bxpc-3 cell. J. Cell. Mol. Med. 2015, 19, 2832-2841. [CrossRef]

112. Kim, Y.R.; Park, M.K.; Kang, G.J.; Kim, H.J.; Kim, E.J.; Byun, H.J.; Lee, M.Y.; Lee, C.H. Leukotriene B4 induces EMT and vimentin expression in PANC-1 pancreatic cancer cells: Involvement of BLT2 via ERK2 activation. Prostaglandins Leukotrienes Essential Fatty Acids 2016, 115, 67-76. [CrossRef]

113. Huang, C.; Xiang, Y.; Chen, S.; Yu, H.; Wen, Z.; Ye, T.; Sun, H.; Kong, H.; Li, D.; Yu, D.; et al. DMKN contributes to the epithelial-mesenchymal transition through increased activation of STAT3 in pancreatic cancer. Cancer Sci. 2017, 108, 2130-2141. [CrossRef]

114. Tang, D.; Zhang, J.; Yuan, Z.; Zhang, H.; Chong, Y.; Huang, Y.; Wang, J.; Xiong, Q.; Wang, S.; Wu, Q.; et al. PSC-derived Galectin-1 inducing epithelial-mesenchymal transition of pancreatic ductal adenocarcinoma cells by activating the NF-kappaB pathway. Oncotarget 2017, 8, 86488-86502. [CrossRef] [PubMed]

115. Xu, X.; Zhao, Z.; Guo, S.; Li, J.; Liu, S.; You, Y.; Ni, B.; Wang, H.; Bie, P. Increased semaphorin 3c expression promotes tumor growth and metastasis in pancreatic ductal adenocarcinoma by activating the ERK1/2 signaling pathway. Cancer Lett. 2017, 397, 12-22. [CrossRef] [PubMed]

116. Zhan, L.; Chen, L.; Chen, Z. Knockdown of FUT3 disrupts the proliferation, migration, tumorigenesis and TGF- $\beta$ induced EMT in pancreatic cancer cells. Oncol. Lett. 2018, 16, 924-930. [CrossRef]

117. Yang, S.; He, P.; Wang, J.; Schetter, A.; Tang, W.; Funamizu, N.; Yanaga, K.; Uwagawa, T.; Satoskar, A.R.; Gaedcke, J.; et al. A Novel MIF signaling pathway drives the malignant character of pancreatic cancer by targeting NR3C2. Cancer Res. 2016, 76, 3838-3850. [CrossRef] [PubMed]

118. Bo, H.; Zhang, S.; Gao, L.; Chen, Y.; Zhang, J.; Chang, X.; Zhu, M. Upregulation of Wnt5a promotes epithelial-to-mesenchymal transition and metastasis of pancreatic cancer cells. BMC Cancer 2013, 13, 496. [CrossRef]

119. Xu, B.; Jin, D.Y.; Lou, W.H.; Wang, D.S. Lipocalin-2 is associated with a good prognosis and reversing epithelial-to-mesenchymal transition in pancreatic cancer. World J. Surg. 2013, 37, 1892-1900. [CrossRef]

120. Cui, L.; Xie, R.; Dang, S.; Zhang, Q.; Mao, S.; Chen, J.; Qu, J.; Zhang, J. NOV promoted the growth and migration of pancreatic cancer cells. Tumor Biol. 2014, 35, 3195-3201. [CrossRef]

121. Meng, F.; Li, W.; Li, C.; Gao, Z.; Guo, K.; Song, S. CCL18 promotes epithelial-mesenchymal transition, invasion and migration of pancreatic cancer cells in pancreatic ductal adenocarcinoma. Int. J. Oncol. 2015, 46, 1109-1120. [CrossRef]

122. Zhou, B.; Zhan, H.; Tin, L.; Liu, S.; Xu, J.; Dong, Y.; Li, X.; Wu, L.; Guo, W. TUFT1 regulates metastasis of pancreatic cancer through HIF1-Snail pathway induced epithelial-mesenchymal transition. Cancer Lett. 2016, 382, 11-20. [CrossRef]

123. Zhang, J.; Zhang, L.; Li, C.; Yang, C.; Li, L.; Song, S.; Wu, H.; Liu, F.; Wang, L.; Gu, J. LOX-1 is a poor prognostic indicator and induces epithelial-mesenchymal transition and metastasis in pancreatic cancer patients. Cell. Oncol. (Dordr.) 2017, 41, 73-84. [CrossRef]

124. Park, J.S.; Lee, J.H.; Lee, Y.S.; Kim, J.K.; Dong, S.M.; Yoon, D.S. Emerging role of LOXL2 in the promotion of pancreas cancer metastasis. Oncotarget 2016, 7, 42539-42552. [CrossRef] [PubMed]

125. Yamaguchi, J.; Yokoyama, Y.; Kokuryo, T.; Ebata, T.; Enomoto, A.; Nagino, M. Trefoil factor 1 inhibits epithelial-mesenchymal transition of pancreatic intraepithelial neoplasm. J. Clin. Investig. 2018, 128, 3619-3629. [CrossRef] [PubMed]

126. Gurbuz, N.; Ashour, A.A.; Alpay, S.N.; Ozpolat, B. Down-regulation of 5-HT1B and 5-HT1D receptors inhibits proliferation, clonogenicity and invasion of human pancreatic cancer cells. PLoS ONE 2014, 9, e110067. [CrossRef] [PubMed] 
127. Subramani, R.; Lopez-Valdez, R.; Arumugam, A.; Nandy, S.; Boopalan, T.; Lakshmanaswamy, R. Targeting insulin-like growth factor 1 receptor inhibits pancreatic cancer growth and metastasis. PLoS ONE 2014, 9, e97016. [CrossRef]

128. Wang, F.; Ma, L.; Zhang, Z.; Liu, X.; Gao, H.; Zhuang, Y.; Yang, P.; Kornmann, M.; Tian, X.; Yang, Y. Hedgehog signaling regulates epithelial-mesenchymal transition in pancreatic cancer stem-like cells. J. Cancer 2016, 7, 408-417. [CrossRef]

129. Liu, C.; Huang, H.; Wang, C.; Kong, Y.; Zhang, H. Involvement of ephrin receptor A4 in pancreatic cancer cell motility and invasion. Oncol. Lett. 2014, 7, 2165-2169. [CrossRef]

130. Tekin, C.; Shi, K.; Daalhuisen, J.B.; Ten Brink, M.S.; Bijlsma, M.F.; Spek, C.A. PAR1 signaling on tumor cells limits tumor growth by maintaining a mesenchymal phenotype in pancreatic cancer. Oncotarget 2018, 9 , 32010-32023. [CrossRef]

131. Miura, S.; Hamada, S.; Masamune, A.; Satoh, K.; Shimosegawa, T. CUB-domain containing protein 1 represses the epithelial phenotype of pancreatic cancer cells. Exp. Cell Res. 2014, 321, 209-218. [CrossRef]

132. Muniyan, S.; Haridas, D.; Chugh, S.; Rachagani, S.; Lakshmanan, I.; Gupta, S.; Seshacharyulu, P.; Smith, L.M.; Ponnusamy, M.P.; Batra, S.K. MUC16 contributes to the metastasis of pancreatic ductal adenocarcinoma through focal adhesion mediated signaling mechanism. Genes Cancer 2016, 7, 110-124. [CrossRef]

133. Belvedere, R.; Bizzarro, V.; Forte, G.; Dal Piaz, F.; Parente, L.; Petrella, A. Annexin A1 contributes to pancreatic cancer cell phenotype, behaviour and metastatic potential independently of Formyl Peptide Receptor pathway. Sci. Rep. 2016, 6, 29660. [CrossRef]

134. Belvedere, R.; Saggese, P.; Pessolano, E.; Memoli, D.; Bizzarro, V.; Rizzo, F.; Parente, L.; Weisz, A.; Petrella, A. miR-196a Is able to restore the aggressive phenotype of annexin a1 knock-out in pancreatic cancer cells by CRISPR/Cas9 genome editing. Int. J. Mol. Sci. 2018, 19, 1967. [CrossRef] [PubMed]

135. Zheng, B.; Ohuchida, K.; Cui, L.; Zhao, M.; Shindo, K.; Fujiwara, K.; Manabe, T.; Torata, N.; Moriyama, T.; Miyasaka, Y.; et al. TM4SF1 as a prognostic marker of pancreatic ductal adenocarcinoma is involved in migration and invasion of cancer cells. Int. J. Oncol. 2015, 47, 490-498. [CrossRef] [PubMed]

136. Ye, C.; Tian, X.; Yue, G.; Yan, L.; Guan, X.; Wang, S.; Hao, C. Suppression of CD26 inhibits growth and metastasis of pancreatic cancer. Tumour Biol 2016, 37, 15677-15686. [CrossRef] [PubMed]

137. Liu, M.; Yang, J.; Zhang, Y.; Zhou, Z.; Cui, X.; Zhang, L.; Fung, K.M.; Zheng, W.; Allard, F.D.; Yee, E.U.; et al. ZIP4 promotes pancreatic cancer progression by repressing ZO-1 and claudin-1 through a ZEB1-dependent transcriptional mechanism. Clin. Cancer Res. Off. J. Am. Assoc. Cancer Res. 2018, 24, 3186-3196. [CrossRef]

138. Huang, S. WAVE3 promotes proliferation, migration and invasion via the AKT pathway in pancreatic cancer. Int. J. Oncol. 2018, 53, 672-684. [CrossRef]

139. Su, H.T.; Weng, C.C.; Hsiao, P.J.; Chen, L.H.; Kuo, T.L.; Chen, Y.W.; Kuo, K.K.; Cheng, K.H. Stem cell marker nestin is critical for TGF-beta1-mediated tumor progression in pancreatic cancer. Mol. Cancer Res. MCR 2013, 11, 768-779. [CrossRef]

140. Hagio, M.; Matsuda, Y.; Suzuki, T.; Ishiwata, T. Nestin regulates epithelial-mesenchymal transition marker expression in pancreatic ductal adenocarcinoma cell lines. Mol. Clin. Oncol. 2013, 1, 83-87. [CrossRef]

141. Razidlo, G.L.; Wang, Y.; Chen, J.; Krueger, E.W.; Billadeau, D.D.; McNiven, M.A. Dynamin 2 potentiates invasive migration of pancreatic tumor cells through stabilization of the Rac1 GEF Vav1. Dev. Cell 2013, 24, 573-585. [CrossRef]

142. Eppinga, R.D.; Krueger, E.W.; Weller, S.G.; Zhang, L.; Cao, H.; McNiven, M.A. Increased expression of the large GTPase dynamin 2 potentiates metastatic migration and invasion of pancreatic ductal carcinoma. Oncogene 2012, 31, 1228-1241. [CrossRef]

143. Igarashi, T.; Araki, K.; Yokobori, T.; Altan, B.; Yamanaka, T.; Ishii, N.; Tsukagoshi, M.; Watanabe, A.; Kubo, N.; Handa, T.; et al. Association of RAB5 overexpression in pancreatic cancer with cancer progression and poor prognosis via E-cadherin suppression. Oncotarget 2017, 8, 12290-12300. [CrossRef]

144. Ashour, A.A.; Gurbuz, N.; Alpay, S.N.; Abdel-Aziz, A.A.; Mansour, A.M.; Huo, L.; Ozpolat, B. Elongation factor-2 kinase regulates TG2/beta1 integrin/Src/uPAR pathway and epithelial-mesenchymal transition mediating pancreatic cancer cells invasion. J. Cell. Mol. Med. 2014, 18, 2235-2251. [CrossRef] [PubMed]

145. Zheng, L.; Zhou, Z.; He, Z. Knockdown of PFTK1 inhibits tumor cell proliferation, invasion and epithelial-to-mesenchymal transition in pancreatic cancer. Int. J. Clin. Exp. Pathol. 2015, 8, 14005-14012. [PubMed] 
146. Tactacan, C.M.; Phua, Y.W.; Liu, L.; Zhang, L.; Humphrey, E.S.; Cowley, M.; Pinese, M.; Biankin, A.V.; Daly, R.J. The pseudokinase SgK223 promotes invasion of pancreatic ductal epithelial cells through JAK1/Stat3 signaling. Mol. Cancer 2015, 14, 139. [CrossRef] [PubMed]

147. Santoro, R.; Zanotto, M.; Carbone, C.; Piro, G.; Tortora, G.; Melisi, D. MEKK3 sustains EMT and stemness in pancreatic cancer by regulating YAP and TAZ transcriptional activity. Anticancer Res. 2018, 38, 1937-1946. [CrossRef]

148. Ungefroren, H.; Sebens, S.; Giehl, K.; Helm, O.; Groth, S.; Fandrich, F.; Rocken, C.; Sipos, B.; Lehnert, H.; Gieseler, F. Rac1b negatively regulates TGF-beta1-induced cell motility in pancreatic ductal epithelial cells by suppressing Smad signaling. Oncotarget 2014, 5, 277-290. [CrossRef]

149. Ning, Z.; Wang, A.; Liang, J.; Xie, Y.; Liu, J.; Yan, Q.; Wang, Z. USP22 promotes epithelial-mesenchymal transition via the FAK pathway in pancreatic cancer cells. Oncol. Rep. 2014, 32, 1451-1458. [CrossRef]

150. Strnadel, J.; Choi, S.; Fujimura, K.; Wang, H.; Zhang, W.; Wyse, M.; Wright, T.; Gross, E.; Peinado, C.; Park, H.W.; et al. eIF5A-PEAK1 signaling regulates YAP1/TAZ protein expression and pancreatic cancer cell growth. Cancer Res. 2017, 77, 1997-2007. [CrossRef]

151. Zhu, L.; Zhao, Q. Hypoxia-inducible factor 1alpha participates in hypoxia-induced epithelial-mesenchymal transition via response gene to complement 32. Exp. Ther. Med. 2017, 14, 1825-1831. [CrossRef]

152. Mody, H.R.; Hung, S.W.; Naidu, K.; Lee, H.; Gilbert, C.A.; Hoang, T.T.; Pathak, R.K.; Manoharan, R.; Muruganandan, S.; Govindarajan, R. SET contributes to the epithelial-mesenchymal transition of pancreatic cancer. Oncotarget 2017, 8, 67966-67979. [CrossRef]

153. Meng, Q.; Shi, S.; Liang, C.; Liang, D.; Hua, J.; Zhang, B.; Xu, J.; Yu, X. Abrogation of glutathione peroxidase-1 drives EMT and chemoresistance in pancreatic cancer by activating ROS-mediated Akt/GSK3beta/Snail signaling. Oncogene 2018, 37, 5843. [CrossRef]

154. Shinke, G.; Yamada, D.; Eguchi, H.; Iwagami, Y.; Asaoka, T.; Noda, T.; Wada, H.; Kawamoto, K.; Gotoh, K.; Kobayashi, S.; et al. Role of histone deacetylase 1 in distant metastasis of pancreatic ductal cancer. Cancer Sci. 2018, 109, 2520-2531. [CrossRef] [PubMed]

155. Mishra, V.K. Histone deacetylase class-I inhibition promotes epithelial gene expression in pancreatic cancer cells in a BRD4- and MYC-dependent manner. Nucleic Acids Res. 2017, 45, 6334-6349. [CrossRef] [PubMed]

156. Ma, C.; Guo, Y.; Zhang, Y.; Duo, A.; Jia, Y.; Liu, C.; Li, B. PAFAH1B2 is a HIF1a target gene and promotes metastasis in pancreatic cancer. Biochem. Biophys. Res. Commun. 2018, 501, 654-660. [CrossRef]

157. Li, S.; Wu, L.; Wang, Q.; Li, Y.; Wang, X. KDM4B promotes epithelial-mesenchymal transition through up-regulation of ZEB1 in pancreatic cancer. Acta Biochim. Biophys. Sin. 2015, 47, 997-1004. [CrossRef] [PubMed]

158. Zhang, W.L.; Zhang, J.H.; Wu, X.Z.; Yan, T.; Lv, W. miR-15b promotes epithelial-mesenchymal transition by inhibiting SMURF2 in pancreatic cancer. Int. J. Oncol. 2015, 47, 1043-1053. [CrossRef] [PubMed]

159. Zhang, J.Q.; Chen, S.; Gu, J.N.; Zhu, Y.; Zhan, Q.; Cheng, D.F.; Chen, H.; Deng, X.X.; Shen, B.Y.; Peng, C.H. MicroRNA-300 promotes apoptosis and inhibits proliferation, migration, invasion and epithelial-mesenchymal transition via the Wnt/beta-catenin signaling pathway by targeting CUL4B in pancreatic cancer cells. J. Cell. Biochem. 2017, 119, 1027-1040. [CrossRef] [PubMed]

160. Viotti, M.; Wilson, C.; McCleland, M.; Koeppen, H.; Haley, B.; Jhunjhunwala, S.; Klijn, C.; Modrusan, Z.; Arnott, D.; Classon, M.; et al. SUV420H2 is an epigenetic regulator of epithelial/mesenchymal states in pancreatic cancer. J. Cell Biol. 2017, 217, 763-777. [CrossRef]

161. Hiraga, R.; Kato, M.; Miyagawa, S.; Kamata, T. Nox4-derived ROS signaling contributes to TGF-beta-induced epithelial-mesenchymal transition in pancreatic cancer cells. Anticancer Res. 2013, 33, 4431-4438.

162. Tan, J.; You, Y.; Xu, T.; Yu, P.; Wu, D.; Deng, H.; Zhang, Y.; Bie, P. Par-4 downregulation confers cisplatin resistance in pancreatic cancer cells via PI3K/Akt pathway-dependent EMT. Toxicol. Lett. 2014, 224, 7-15. [CrossRef]

163. Zhao, J.; Wang, Y.; Wu, X. HMGN5 promotes proliferation and invasion via the activation of Wnt/ $\beta$-catenin signaling pathway in pancreatic ductal adenocarcinoma. Oncol. Lett. 2018, 16, 4013-4019. [CrossRef]

164. Song, Y.X.; Xu, Z.C.; Li, H.L.; Yang, P.L.; Du, J.K.; Xu, J. Overexpression of GP73 promotes cell invasion, migration and metastasis by inducing epithelial-mesenchymal transition in pancreatic cancer. Pancreatology 2018, 18, 812-821. [CrossRef] [PubMed] 
165. Xu, X.; Su, B.; Xie, C.; Wei, S.; Zhou, Y.; Liu, H.; Dai, W.; Cheng, P.; Wang, F.; Xu, X.; et al. Sonic hedgehog-Gli1 signaling pathway regulates the epithelial mesenchymal transition (EMT) by mediating a new target gene, S100A4, in pancreatic cancer cells. PLoS ONE 2014, 9, e96441. [CrossRef] [PubMed]

166. Inaguma, S.; Kasai, K.; Ikeda, H. GLI1 facilitates the migration and invasion of pancreatic cancer cells through MUC5AC-mediated attenuation of E-cadherin. Oncogene 2011, 30, 714-723. [CrossRef] [PubMed]

167. Nagai, S.; Nakamura, M.; Yanai, K.; Wada, J.; Akiyoshi, T.; Nakashima, H.; Ohuchida, K.; Sato, N.; Tanaka, M.; Katano, M. Gli1 contributes to the invasiveness of pancreatic cancer through matrix metalloproteinase-9 activation. Cancer Sci. 2008, 99, 1377-1384. [CrossRef]

168. Inaguma, S.; Kasai, K.; Hashimoto, M.; Ikeda, H. GLI1 modulates EMT in pancreatic cancer-Letter. Cancer Res. 2012, 72, 3702-3703. [CrossRef]

169. Huang, C.; Xie, D.; Cui, J.; Li, Q.; Gao, Y.; Xie, K. FOXM1c promotes pancreatic cancer epithelialto-mesenchymal transition and metastasis via upregulation of expression of the urokinase plasminogen activator system. Clin. Cancer Res. Off. J. Am. Assoc. Cancer Res. 2014, 20, 1477-1488. [CrossRef]

170. Xie, D.; Cui, J.; Xia, T.; Jia, Z.; Wang, L.; Wei, W.; Zhu, A.; Gao, Y.; Xie, K.; Quan, M. Hippo transducer TAZ promotes epithelial mesenchymal transition and supports pancreatic cancer progression. Oncotarget 2015, 6, 35949-35963. [CrossRef]

171. Yuan, Y.; Li, D.; Li, H.; Wang, L.; Tian, G.; Dong, Y. YAP overexpression promotes the epithelial-mesenchymal transition and chemoresistance in pancreatic cancer cells. Mol. Med. Rep. 2016, 13, 237-242. [CrossRef]

172. Chen, K.; Qian, W.; Li, J.; Jiang, Z.; Cheng, L.; Yan, B.; Cao, J.; Sun, L.; Zhou, C.; Lei, M.; et al. Loss of AMPK activation promotes the invasion and metastasis of pancreatic cancer through an HSF1-dependent pathway. Mol. Oncol. 2017, 11, 1475-1492. [CrossRef]

173. Subramani, R.; Camacho, F.A.; Levin, C.I.; Flores, K.; Clift, A.; Galvez, A.; Terres, M.; Rivera, S.; Kolli, S.N.; Dodderer, J.; et al. FOXC1 plays a crucial role in the growth of pancreatic cancer. Oncogenesis 2018, 7, 52. [CrossRef]

174. Li, X.; Chen, H.; Liu, Z.; Ye, Z.; Gou, S.; Wang, C. Overexpression of MIST1 reverses the epithelial-mesenchymal transition and reduces the tumorigenicity of pancreatic cancer cells via the Snail/E-cadherin pathway. Cancer Lett. 2018, 431, 96-104. [CrossRef] [PubMed]

175. Yi, X.; Zai, H.; Long, X.; Wang, X.; Li, W.; Li, Y. Kruppel-like factor 8 induces epithelial-to-mesenchymal transition and promotes invasion of pancreatic cancer cells through transcriptional activation of four and a half LIM-only protein 2. Oncol. Lett. 2017, 14, 4883-4889. [CrossRef] [PubMed]

176. Thakur, A.K.; Nigri, J.; Lac, S.; Leca, J.; Bressy, C.; Berthezene, P.; Bartholin, L.; Chan, P.; Calvo, E.; Iovanna, J.L.; et al. TAp73 loss favors Smad-independent TGF- $\beta$ signaling that drives EMT in pancreatic ductal adenocarcinoma. Cell Death Differ. 2016, 23, 1358-1370. [CrossRef] [PubMed]

177. Takano, S.; Reichert, M.; Bakir, B.; Das, K.K.; Nishida, T.; Miyazaki, M.; Heeg, S.; Collins, M.A.; Marchand, B.; Hicks, P.D.; et al. Prrx1 isoform switching regulates pancreatic cancer invasion and metastatic colonization. Genes Dev. 2016, 30, 233-247. [CrossRef] [PubMed]

178. Yu, C.; Zhan, L.; Jiang, J.; Pan, Y.; Zhang, H.; Li, X.; Pen, F.; Wang, M.; Qin, R.; Sun, C. KAP-1 is overexpressed and correlates with increased metastatic ability and tumorigenicity in pancreatic cancer. Med. Oncol. (Northwood Lond. Engl.) 2014, 31, 25. [CrossRef]

179. Li, C.; Wang, Z.; Chen, Y.; Zhou, M.; Zhang, H.; Chen, R.; Shi, F.; Wang, C.; Rui, Z. Transcriptional silencing of ETS-1 abrogates epithelial-mesenchymal transition resulting in reduced motility of pancreatic cancer cells. Oncol. Rep. 2015, 33, 559-565. [CrossRef]

180. Arfmann-Knubel, S.; Struck, B.; Genrich, G.; Helm, O.; Sipos, B.; Sebens, S.; Schafer, H. The Crosstalk between Nrf2 and TGF-beta1 in the epithelial-mesenchymal transition of pancreatic duct epithelial cells. PLoS ONE 2015, 10, e0132978. [CrossRef]

181. Roy, N.; Takeuchi, K.K.; Ruggeri, J.M.; Bailey, P.; Chang, D.; Li, J.; Leonhardt, L.; Puri, S.; Hoffman, M.T.; Gao, S.; et al. PDX1 dynamically regulates pancreatic ductal adenocarcinoma initiation and maintenance. Genes Dev. 2016, 30, 2669-2683. [CrossRef]

182. Sannino, G.; Armbruster, N.; Bodenhofer, M.; Haerle, U.; Behrens, D.; Buchholz, M.; Rothbauer, U.; Sipos, B.; Schmees, C. Role of BCL9L in transforming growth factor-beta (TGF-beta)-induced epithelial-to-mesenchymal-transition (EMT) and metastasis of pancreatic cancer. Oncotarget 2016, 7, 73725-73738. [CrossRef] 
183. Heeg, S.; Das, K.K.; Reichert, M.; Bakir, B.; Takano, S.; Caspers, J.; Aiello, N.M.; Wu, K.; Neesse, A.; Maitra, A.; et al. ETS-Transcription Factor ETV1 Regulates Stromal Expansion and Metastasis in Pancreatic Cancer. Gastroenterology 2016, 151, 540-553.e14. [CrossRef]

184. Yang, J.; Zhang, X.; Zhang, Y.; Zhu, D.; Zhang, L.; Li, Y.; Zhu, Y.; Li, D.; Zhou, J. HIF-2alpha promotes epithelial-mesenchymal transition through regulating Twist2 binding to the promoter of E-cadherin in pancreatic cancer. J. Exp. Clin. Cancer Res. CR 2016, 35, 26. [CrossRef] [PubMed]

185. Lerbs, T.; Bisht, S.; Scholch, S.; Pecqueux, M.; Kristiansen, G.; Schneider, M.; Hofmann, B.T.; Welsch, T.; Reissfelder, C.; Rahbari, N.N.; et al. Inhibition of Six1 affects tumour invasion and the expression of cancer stem cell markers in pancreatic cancer. BMC Cancer 2017, 17, 249. [CrossRef] [PubMed]

186. Nishino, H.; Takano, S.; Yoshitomi, H.; Suzuki, K.; Kagawa, S.; Shimazaki, R.; Shimizu, H.; Furukawa, K.; Miyazaki, M.; Ohtsuka, M. Grainyhead-like 2 (GRHL2) regulates epithelial plasticity in pancreatic cancer progression. Cancer Med. 2017, 6, 2686-2696. [CrossRef]

187. Martinelli, P.; Carrillo-de Santa Pau, E.; Cox, T.; Sainz, B., Jr.; Dusetti, N.; Greenhalf, W.; Rinaldi, L.; Costello, E.; Ghaneh, P.; Malats, N.; et al. GATA6 regulates EMT and tumour dissemination, and is a marker of response to adjuvant chemotherapy in pancreatic cancer. Gut 2017, 66, 1665-1676. [CrossRef] [PubMed]

188. Dai, S.; Zhang, J.; Huang, S.; Lou, B.; Fang, B.; Ye, T.; Huang, X.; Chen, B.; Zhou, M. HNRNPA2B1 regulates the epithelial-mesenchymal transition in pancreatic cancer cells through the ERK/snail signaling pathway. Cancer Cell. Int. 2017, 17, 12. [CrossRef] [PubMed]

189. Chen, J.; Sun, Y.; Xu, X.; Wang, D.; He, J.; Zhou, H.; Lu, Y.; Zeng, J.; Du, F.; Gong, A.; et al. YTH domain family 2 orchestrates epithelial-mesenchymal transition/proliferation dichotomy in pancreatic cancer cells. Cell Cycle 2017, 16, 2259-2271. [CrossRef]

190. Zhao, L.; Sun, H.; Kong, H.; Chen, Z.; Chen, B.; Zhou, M. The Lncrna-TUG1/EZH2 Axis promotes pancreatic cancer cell proliferation, migration and EMT phenotype formation through sponging Mir-382. Cell. Physiol. Biochem. Int. J. Exp. Cell. Physiol. Biochem. Pharmacol. 2017, 42, 2145-2158. [CrossRef]

191. Gao, Y.; Zhang, Z.; Li, K.; Gong, L.; Yang, Q.; Huang, X.; Hong, C.; Ding, M.; Yang, H. Linc-DYNC2H1-4 promotes EMT and CSC phenotypes by acting as a sponge of miR-145 in pancreatic cancer cells. Cell Death Dis. 2017, 8, e2924. [CrossRef]

192. Wu, G.; Li, Z.; Jiang, P.; Zhang, X.; Xu, Y.; Chen, K.; Li, X. MicroRNA-23a promotes pancreatic cancer metastasis by targeting epithelial splicing regulator protein 1. Oncotarget 2017, 8, 82854-82871. [CrossRef]

193. Li, H.; Wang, X.; Wen, C.; Huo, Z.; Wang, W.; Zhan, Q.; Cheng, D.; Chen, H.; Deng, X.; Peng, C.; et al. Long noncoding RNA NORAD, a novel competing endogenous RNA, enhances the hypoxia-induced epithelial-mesenchymal transition to promote metastasis in pancreatic cancer. Mol. Cancer 2017, 16, 169. [CrossRef]

194. Ma, C.; Nong, K.; Zhu, H.; Wang, W.; Huang, X.; Yuan, Z.; Ai, K. H19 promotes pancreatic cancer metastasis by derepressing let-7's suppression on its target HMGA2-mediated EMT. Tumor Biol. 2014, 35, 9163-9169. [CrossRef] [PubMed]

195. Zhan, H.X.; Wang, Y.; Li, C.; Xu, J.W.; Zhou, B.; Zhu, J.K.; Han, H.F.; Wang, L.; Wang, Y.S.; Hu, S.Y. LincRNA-ROR promotes invasion, metastasis and tumor growth in pancreatic cancer through activating ZEB1 pathway. Cancer Lett. 2016, 374, 261-271. [CrossRef] [PubMed]

196. Hu, J.; Li, L.; Chen, H.; Zhang, G.; Liu, H.; Kong, R.; Chen, H.; Wang, Y.; Li, Y.; Tian, F.; et al. MiR-361-3p regulates ERK1/2-induced EMT via DUSP2 mRNA degradation in pancreatic ductal adenocarcinoma. Cell Death Dis. 2018, 9, 807. [CrossRef] [PubMed]

197. Li, N.; Wang, C.; Zhang, P.; You, S. Emodin inhibits pancreatic cancer EMT and invasion by up-regulating microRNA-1271. Mol. Med. Rep. 2018, 18, 3366-3374. [CrossRef] [PubMed]

198. Little, E.C.; Camp, E.R.; Wang, C.; Watson, P.M.; Watson, D.K.; Cole, D.J. The CaSm (LSm1) oncogene promotes transformation, chemoresistance and metastasis of pancreatic cancer cells. Oncogenesis 2016, 5, e182. [CrossRef] [PubMed]

199. Suzuki, K.; Takano, S.; Yoshitomi, H.; Nishino, H.; Kagawa, S.; Shimizu, H.; Furukawa, K.; Miyazaki, M.; Ohtsuka, M. Metadherin promotes metastasis by supporting putative cancer stem cell properties and epithelial plasticity in pancreatic cancer. Oncotarget 2017, 8, 66098-66111. [CrossRef] [PubMed] 
200. Fabregat, A.; Jupe, S.; Matthews, L.; Sidiropoulos, K.; Gillespie, M.; Garapati, P.; Haw, R.; Jassal, B.; Korninger, F.; May, B.; et al. The Reactome Pathway Knowledgebase. Nucleic Acids Res. 2018, 46, D649-D655. [CrossRef]

201. Kelder, T.; Pico, A.R.; Hanspers, K.; van Iersel, M.P.; Evelo, C.; Conklin, B.R. Mining biological pathways using WikiPathways web services. PLoS ONE 2009, 4, e6447. [CrossRef]

202. Szklarczyk, D.; Gable, A.L.; Lyon, D.; Junge, A.; Wyder, S.; Huerta-Cepas, J.; Simonovic, M.; Doncheva, N.T.; Morris, J.H.; Bork, P.; et al. STRING v11: Protein-protein association networks with increased coverage, supporting functional discovery in genome-wide experimental datasets. Nucleic Acids Res. 2019, 47, D607-D613. [CrossRef]

203. Shannon, P.; Markiel, A.; Ozier, O.; Baliga, N.S.; Wang, J.T.; Ramage, D.; Amin, N.; Schwikowski, B.; Ideker, T. Cytoscape: A software environment for integrated models of biomolecular interaction networks. Genome Res. 2003, 13, 2498-2504. [CrossRef]

204. Maresch, R.; Mueller, S.; Veltkamp, C.; Ollinger, R.; Friedrich, M.; Heid, I.; Steiger, K.; Weber, J.; Engleitner, T.; Barenboim, M.; et al. Multiplexed pancreatic genome engineering and cancer induction by transfection-based CRISPR/Cas9 delivery in mice. Nat. Commun. 2016, 7, 10770. [CrossRef] [PubMed]

(C) 2019 by the authors. Licensee MDPI, Basel, Switzerland. This article is an open access article distributed under the terms and conditions of the Creative Commons Attribution (CC BY) license (http://creativecommons.org/licenses/by/4.0/). 